\title{
JOAQUÍN VAQUERO PALACIOS EN NUEVA YORK
}

\author{
Francisco Egaña CASARIEGo \\ Universidad de Valladolid
}

\begin{abstract}
El autor reconstruye las estancias en Nueva York del joven arquitecto y pintor Joaquín Vaquero Palacios (Oviedo, 1900-Madrid, 1998) entre los años 1928 y 1930. Si su consideración de pensionado por la Junta para Ampliación de Estudios le facilitó el acceso a los últimos rascacielos, su vocación plástica le llevó a pintar paisajes urbanos y a ilustrar con sus dibujos la edición norteamericana e inglesa del libro New York, del escritor francés Paul Morand. Por lo demás, su estancia en la gran metrópoli le permitió conocer su ambiente artístico y cultural, así como exhibir sus paisajes de España en importantes galerías y centros culturales.
\end{abstract}

Palabras clave: Joaquín Vaquero Palacios; Nueva York; Pintura.

\section{JOAQUÍN VAQUERO PALACIOS IN NEW YORK}

The author reconstructs the different visits of the young architect and painter Joaquín Vaquero Palacios (Oviedo, 1900-Madrid, 1998) to New York between 1928 and 1930. While his scholarship from the Junta para Ampliación de Estudios permitted him access to the most recent skyscrapers constructed in the city, his artistic calling led him to paint urban landscapes and provide drawings to illustrate the American and British editions of New York by the French writer Paul Morand. In addition, his stay in the great metropolis allowed him to experience this special cultural and artistic environment, and provided him with the opportunity to exhibit his Spanish landscapes in important galleries and cultural centres.

Key words: Joaquín Vaquero Palacios; New York; Painting.

En los últimos años la historiografía española ha venido prestando una atención creciente a los viajes de los artistas, estudios que se han concretado en seminarios, cursos y congresos donde ha quedado patente no sólo su interés para entender la gramática personal de estos creadores, sino también para la difusión de ideas renovadoras en nuestro país. Dentro de estos han merecido especial atención los dedicados a los viajes realizados por los arquitectos españoles durante el primer tercio del siglo XX, cada vez más habituales a medida que avanzaba el siglo y determinantes en la puesta al día de nuestra arquitectura ${ }^{1}$.

Si durante este periodo los viajes europeos de nuestros arquitectos no fueron del todo infrecuentes -sobre todo los realizados a Holanda, Francia y Alemania-, los transoceánicos resultaron

AVS $=$ Archivo Vaquero Segovia

${ }^{1}$ Uno de los foros de encuentro y discusión más relevantes en este sentido ha sido el VII Congreso Internacional de Arquitectura Moderna española organizado recientemente por la Escuela de Arquitectura de Navarra bajo el título Viajes en la transición de la arquitectura española hacia la modernidad. Véase Pozo y García Diego, 2010. 
algo excepcional ${ }^{2}$. En este sentido la figura del asturiano Joaquín Vaquero Palacios resulta paradigmática, pues encarna el prototipo del viajero incansable por tierras de Europa y América en busca de estímulos nuevos para su obra. Su doble condición de arquitecto y pintor motivará que los mismos estímulos provoquen reacciones múltiples, al permanecer sensible no sólo a los aspectos puramente formales o tecnológicos de los edificios que encuentre a su paso, y que incorporará a su léxico arquitectónico de vanguardia, sino también a sus valores plásticos y emocionales. Ello le incitará a dibujar y a pintar estas construcciones, constituyendo los paisajes arquitectónicos uno de los registros más característicos de su personalidad artística y merecedor por sí mismo de un estudio monográfico.

Su vinculación con América, que será una constante a lo largo de su trayectoria, se inició tempranamente en Nueva York, recién terminados sus estudios de arquitectura, de donde pasó a Jamaica, Guatemala, El Salvador, Panamá, Colombia y Cuba, para retornar nuevamente a los Estados Unidos. Esta relación con América se vio favorecida por su matrimonio con la salvadoreña Rosa Turcios Darío, sobrina carnal del poeta nicaragüense Rubén Darío, que actuó como puente de unión entre el Viejo y el Nuevo Mundo.

El estudio de la ajetreada andadura de este artista se ve facilitada por la documentación conservada en su archivo personal. Y es que a lo largo de su vida Vaquero mostró un extraordinario celo en conservar recuerdos de sus viajes, desde pasajes de avión o de barco hasta facturas de hoteles, entradas para museos, fotografías, cartas de amigos y anotaciones de paisajes vistos, documentos que constituyen hoy una inestimable ayuda para la reconstrucción de su periplo vital y artístico. Además, a lo largo de las últimas décadas de su vida Vaquero pensó en escribir su autobiografía, aprovechando dietarios atrasados y viejas agendas donde, como paso previo, iba ordenando por fechas aquellos datos y anécdotas que consideraba importantes en su vida. Pero sus numerosas ocupaciones y, finalmente, su avanzada edad frustraron cualquier intento de sistematización. Estas anotaciones autobiográficas, unidas a los relatos personales que escribió en determinadas circunstancias de su vida -viajes, trabajos arquitectónicos, estudios históricos...- constituyen una fuente imprescindible y de primera mano para cualquier intento de aproximación a su vasta obra. Una obra que el crítico de arte V. Aguilera Cerni definió, acertadamente, como "una crónica de su contacto con el mundo"'.

\section{Los años de formación en Madrid: Una vocación plural}

Nacido en Oviedo en 1900, Joaquín Vaquero mostró desde su infancia una firme vocación artística que le llevó a pintar y a exponer desde una edad muy temprana. Terminado el bachillerato, a los dieciocho años se trasladó a Madrid para preparar el ingreso en la Escuela de Arquitectura en lugar de matricularse en una escuela de arte. En esa decisión pesó la influencia paterna, que deseaba que cursara una carrera universitaria. Pero también la convicción del propio joven, que consideraba la arquitectura como la mejor formación para un pintor paisajista, consciente de que la disciplina de la línea y el manejo de los planos y de los volúmenes le conducirían hacia un mayor equilibrio en la composición y a una mayor claridad en la interpretación de las formas ${ }^{4}$.

Durante los años de preparatorio del ingreso en la Escuela dibuja y pinta sin cesar, iniciando el envío periódico de sus obras a las Exposiciones Nacionales. En 1922 ingresó en la Escuela de

\footnotetext{
2 Sobre los viajes de los arquitectos españoles a Estados Unidos, v. SAn Antonio Gómez, 2001: 71 y 76-81.

3 Aguilera Cerni, 1980: 23.

${ }^{4}$ Declaración del artista, recogida en García BANDRÉs, 1979.
} 
Arquitectura, donde tuvo por compañeros de promoción a Luis Moya Blanco, Vicente Eced, Luis Martínez Feduchi, Felipe López Delgado, José Blein, Vidal Sainz Heres y José Manuel de Aizpúrua. Como profesores de su reducida promoción cabría destacar los nombres de Teodoro Anasagasti, Modesto López Otero, Juan Moya, Carlos Gato y César Cort 5 .

En la Escuela siguió los cursos sin una aplicación notable - pero sin ningún tropiezo- para dedicar todo su tiempo libre a pintar y a visitar los museos de la capital. Si el Prado le familiarizó con la gran tradición española, fue el Museo de Arte Moderno el que más le interesó y donde pudo admirar la obra de los pintores que más se aproximaban a su concepto pictórico: Joaquín Sorolla y Joaquín Mir. Como complemento de esta formación frecuentó los estudios de Vázquez Díaz, Sorolla, Solana, los Zubiaurre, Victorio Macho, Juan de Echevarría, Ricardo Baroja y del asturiano José Ramón Zaragoza, a cuyas clases de dibujo asistió durante algún tiempo.

Paralelamente a sus estudios de arquitectura, desarrolló una intensa actividad pictórica en Madrid y sus alrededores atraído por su luz blanca característica. Vaquero pintó sus calles y plazas barrocas, así como los paisajes rurales de Canillejas, a donde acudía con alguna frecuencia en compañía de Luis Moya para dibujar y tomar apuntes. En plena época del excursionismo pictórico, los fines de semana le brindaban la oportunidad de plantar su caballete frente a las murallas e iglesias de algunas viejas ciudades castellanas como Segovia o Ávila.

Pero será durante el verano cuando pinte con mayor asiduidad. Concluido el curso en Madrid acudía a Somiedo, región montañosa de Asturias lindante con León, para reunirse con su familia y pasar allí las vacaciones estivales. Su padre, técnico de obras públicas y figura destacada en la dotación de agua y luz a la capital asturiana, llevaba a cabo durante los veranos sus trabajos de campo para la construcción del Salto de agua de Somiedo y, cuando llegaban las vacaciones, la familia entera se trasladaba con él a la montaña. Aquellos veranos le permitieron pintar intensamente en torno a este tramo de la Cordillera Cantábrica que goza del clima y de la luz de Castilla. Muy de mañana -como ha relatado en más de una ocasión- tomaba dos caballos, en uno de los cuales cargaba sus bártulos de pintar y el otro lo utilizaba como cabalgadura, para recorrer aquellas altas montañas en busca de asuntos pictóricos. Cuando ya anocheciendo regresaba a casa, había pintado varias composiciones sobre las que no insistía ni realizaba correcciones posteriores ${ }^{6}$. Los refugios veraniegos de los vaqueiros de alzada, sus lagos y brañas, así como las pequeñas aldeas situadas a una altitud de más de dos mil metros, constituyeron sus motivos preferentes que plasmaba en obras de pequeño formato, casi siempre óleos sobre cartón de 38 x $46 \mathrm{~cm}$. Su estilo, cercano al impresionismo, se sustentaba en la importancia otorgada a la mancha y el colorido cálido y brillante, lo que provocará el desconcierto de la crítica cuando exponga estas pinturas en Oviedo ${ }^{7}$.

En 1926, un año antes de concluir sus estudios de arquitectura, celebró su primera exposición individual en Madrid. La muestra se inauguró en el mes de marzo en las salas del Museo de Arte Moderno, asistiendo al acto su director, el escultor Mariano Benlliure, y otras relevantes personalidades de la vida cultural madrileña ${ }^{8}$. Aquel conjunto de setenta paisajes de Asturias, Castilla y Madrid llamó poderosamente la atención de la crítica, que coincidió en destacar las excelentes

\footnotetext{
5 AVS. Vaquero Palacios, Biografía desde 1916 hasta 1986 (incompleta), ms, p. 18.

${ }^{6}$ AVS. Vaquero Palacios, Relatos de mi vida, carp. I, n. ${ }^{\circ} 14$, s. f.

${ }^{7}$ FonseCA, 1924; BRAdomín, 1924.

8 "Exposición de paisajes", La Libertad, Madrid, 13-III-1926; "La exposición del pintor Vaquero", La Nación, Buenos Aires, 13-III-1926; "Arte y artistas. Exposición Joaquín Vaquero", $A B C$, Madrid, 14-III-1926; "Arte y artistas”, $A B C$, Madrid, 15-III-1926; "Exposición Vaquero", Nuevo Mundo, Madrid, 20-III-1926; "Exposición Vaquero", La Prensa, Gijón. 26-III-1926; "La exposición del pintor Vaquero", La Nación, Madrid, 26-III-1926; "La Infanta Isabel visita la exposición del paisajista ovetense Sr. Vaquero", El Carbayón, Oviedo, 28-III-1926; “Joaquín Vaquero”, Heraldo de Madrid, 6-IV-1926.
}

Arch. esp. arte, LXXXVI, 343, JULIO-SEPTIEMBRE 2013, 237-262, ISSN: 0004-0428 
dotes de pintor del joven estudiante de arquitectura ${ }^{9}$. Teodoro Anasagasti, su profesor más admirado en la Escuela, le dedicó una reseña en las páginas de la revista Arquitectura en la que le señalaba como paradigma de la dimensión humanística que debería asumir, a su juicio, el moderno profesional de la arquitectura ${ }^{10}$.

Ese mismo año conoció en Madrid a la que dos años más tarde se convertiría en su esposa, la salvadoreña Rosa Turcios Darío, sobrina carnal del poeta Rubén Darío. Fue su compañero de curso en la Escuela y gran amigo José Manuel Aizpúrua quien se la presentó en el Hotel Calero de la Gran Vía, donde se hospedaban ambos estudiantes. En una de sus conversaciones, Aizpúrua le refirió que había conocido en Hendaya a una joven centroamericana que se hallaba con su hermana y su cuñado, el poeta Alberto Guerra Trigueros, pasando una temporada al lado de Miguel de Unamuno en su exilio. Teniendo previsto viajar a Madrid, les había recomendado el Hotel Calero, indicándole que eran muy aficionados a la pintura y que llegarían de un día a otro. A los pocos días llegó para alojarse en el hotel el matrimonio Guerra Trigueros con sus dos hijas de corta edad y su hermana soltera. Ya desde sus primeras conversaciones, Vaquero tuvo el presentimiento de que su vida quedaría vinculada para siempre a la de aquella joven salvadoreña ${ }^{11}$.

En abril de 1927, durante unas cortas vacaciones de su último curso de arquitectura, conoció accidentalmente en Oviedo, dibujando frente a la catedral, al célebre artista escocés Muirhead Bone, que se hallaba recorriendo nuestro país para concluir su monumental obra de dibujos Old Spain, editada años después en Londres ${ }^{12}$. A partir de este primer encuentro, y a pesar de las diferencias de edad y de idioma, surgió entre ambos una sincera amistad que se mantendría hasta la muerte del dibujante y grabador en 1953. Bone le llevó a la pensión de la calle de Jovellanos donde se hospedaba con su mujer, Gertrude, obsequiándole algunos de sus dibujos. Días después viajó con él a Astorga en ferrocarril, dibujando ambos durante el trayecto a través de las ventanillas ${ }^{13}$. El joven le confesó su deseo de probar suerte en París como pintor una vez concluyera sus estudios de arquitectura, algo a lo que le animó vivamente el veterano artista, entregándole una serie de cartas de presentación para algunas galerías por si pudieran facilitarle las cosas.

\section{De París a Nueva York (1928)}

Finalizados sus estudios en junio de 1927, Vaquero retornó a Oviedo para preparar su aventura parisina. El 10 de septiembre empaquetó un conjunto de treinta cartones con paisajes de Asturias, Castilla y Madrid y tomó rumbo a la capital francesa donde le esperaba Rosa Turcios (fig. 1) con su hermana Margot, su marido y sus hijas Teresa y Dora.

Una vez allí inició su recorrido por algunas modestas galerías de la rue de la Boetie, sin obtener en ninguna de ellas una invitación para exponer su obra. A punto ya de perder toda esperanza, el 17 de septiembre se decidió a probar suerte en la prestigiosa galería Knoedler de la Place Vendôme, una sucursal de la galería neoyorquina homónima para la que llevaba una carta de presentación de M. Bone que hasta ese momento, por modestia, había rehusado utilizar ${ }^{14}$. El encargado le comunicó que Charles M. Henshel, director de la sala Knoedler de Nueva York, llegaría a París en unos días,

\footnotetext{
9 Alcántara, 1926. El crítico de arte E. Teroll, corresponsal de The Art News, ensalzó la fuerza y la simplicidad de aquellos paisajes arquitectónicos pintados bajo un sol radiante, para terminar considerando la muestra del joven pintor como una de las más interesantes de las realizadas en Madrid en mucho tiempo. E. Teroll, 1926.

10 Anasagasti, 1926: 165-166.

11 AVS. Vaquero Palacios, Relatos de mi vida, carp. I, n. ${ }^{\circ}$ 24, s. p. Gómez Santos, 1974: 168-170.

${ }^{12}$ El libro, que incluía los textos de su mujer, Gertrude, fue publicado en 1936 por la editorial Macmillan and Co.

13 AVS. Vaquero Palacios, Relatos de mi vida, carp. I, n. ${ }^{\circ}$ 24, s. p.

14 AVS. Vaquero Palacios, Diario 1927-1928 (20-IX-1927), ms.
} 
por lo que le instaba a volver cuando estuviera él. Joaquín Vaquero aprovechó la espera para pintar alguna vista del Sena y recorrer París, una ciudad que conocía ya por su visita a la Exposición Internacional de Artes Decorativas de $1925^{15}$.

El veinte de septiembre, fecha del anuncio de la llegada de Mr. Henschel, llevó sus cuadros a la galería ${ }^{16}$. Allí pudo contemplar éste su obra en una improvisada exposición, con los cartones sin marco apoyados sobre los muebles de su despacho. Admirado por la calidad y frescura de sus paisajes, le invitó a mostrar su obra en la galería Knoedler de Nueva York, fijando desde ese mismo momento fecha para la exposición: enero de $1928^{17}$. Joaquín Vaquero no cabía en sí de alegría. Aquella invitación constituía una ocasión única para un joven pintor como él. Además, el viaje a Nueva York le permitiría conocer los modernos rascacielos que tanto le fascinaban y que conocía a través de revistas de arquitectura americanas a las que se hallaba suscrito ${ }^{18}$. Para ello solicitó la consideración de pensionado por la Junta para Ampliación de Estudios, lo que a pesar de no conllevar una ayuda económica le facilitaría las cartas de presentación necesarias para acceder al estudio de aquellas gigantescas estructuras $^{19}$. A principios del mes de octubre,

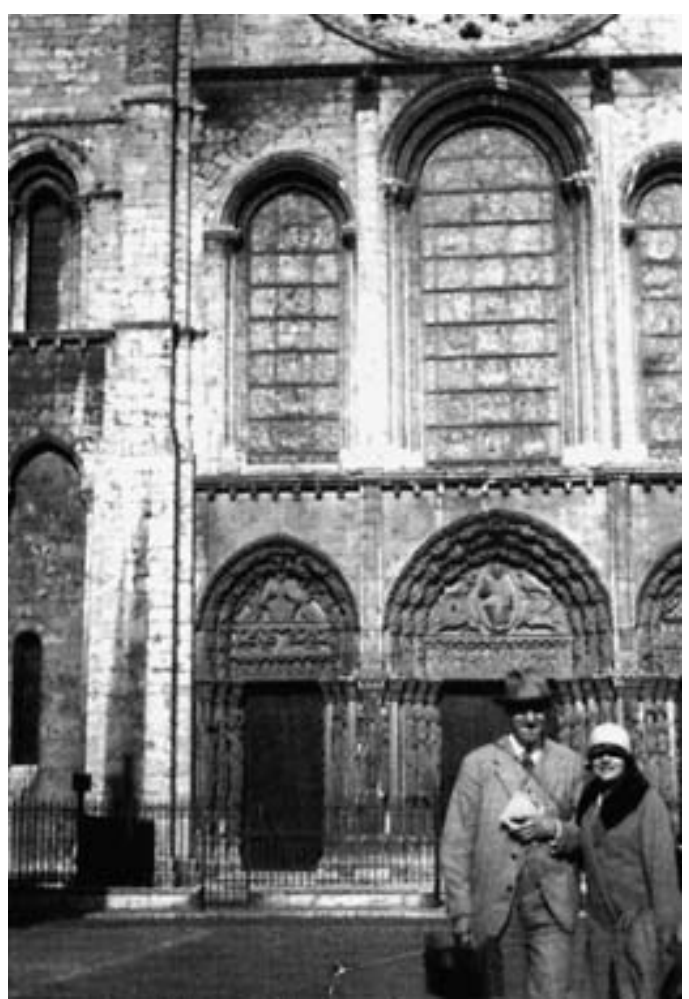

Fig. 1. Joaquín Vaquero con Rosa Turcios en Chartres (junio de 1927). antes de retornar a España para preparar el embarque de sus cuadros y despedirse de su familia, viajó a Amberes, Gante y Brujas, donde pintó algunos paisajes arquitectónicos (fig. 2).

De regreso a Asturias embaló y facturó en el puerto de Gijón noventa cuadros con destino a Nueva York, para tomar seguidamente un tren hacia París donde le aguardaba su ya prometida, Rosa. Ésta había condicionado el matrimonio a que viajase a San Salvador para conocer a su familia y celebrar allí el enlace. Acompañados de la familia Guerra Trigueros viajaron en tren hasta el puerto de El Havre, donde se embarcaron en el transatlántico Rochambeau rumbo a Nueva York.

15 Vaquero viajó a París en agosto de 1925 acompañado de su cuñado, el también pintor y arquitecto Francisco Casariego Terrero. Uno de los pabellones que más le impactó en la exposición fue el Pabellón de Turismo, obra del arquitecto Robert Mallet-Stevens, como se deduce no sólo del número de veces que se fotografió delante de él, sino también de la influencia que ejerció esta arquitectura funcional en sus primeras obras proyectadas en Oviedo.

16 AVS. Vaquero Palacios, Diario 1927-1928 (20-IX-1927).

17 AVS. Vaquero Palacios, Relatos de mi vida, carp. I, n. ${ }^{\circ} 24$, s. p.

${ }^{18}$ Durante su etapa de estudiante, Vaquero estuvo suscrito a la revista Architectural Record.

${ }^{19}$ En el archivo de la Junta de Ampliación de Estudios (carpeta 1942, exp. 147-62) se conservan la ficha y la carta de solicitud de Vaquero, firmada el 5 de septiembre de 1927, a quien concedieron la equiparación de pensionado por un año el día veintiuno de ese mismo mes (archivojae.edaddeplata.org/jae_app/JaeMain.html). Vaquero recibió la notificación oficial de la Junta a través de un oficio remitido por su secretario, don José Castillejo y Duarte, fechado el 7 de octubre de 1927 en Madrid. AVS: Vaquero Palacios, Diario 1927-1928, s. p. 


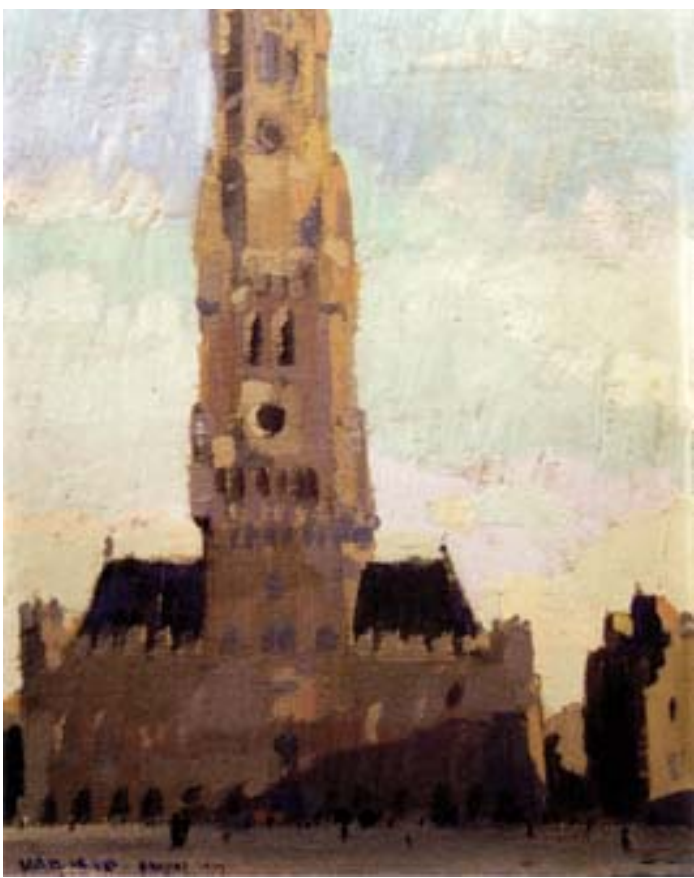

Fig. 2. Joaquín Vaquero, Ayuntamiento de Brujas, 1927 (octubre). Óleo sobre cartón, 41 x $33 \mathrm{~cm}$.

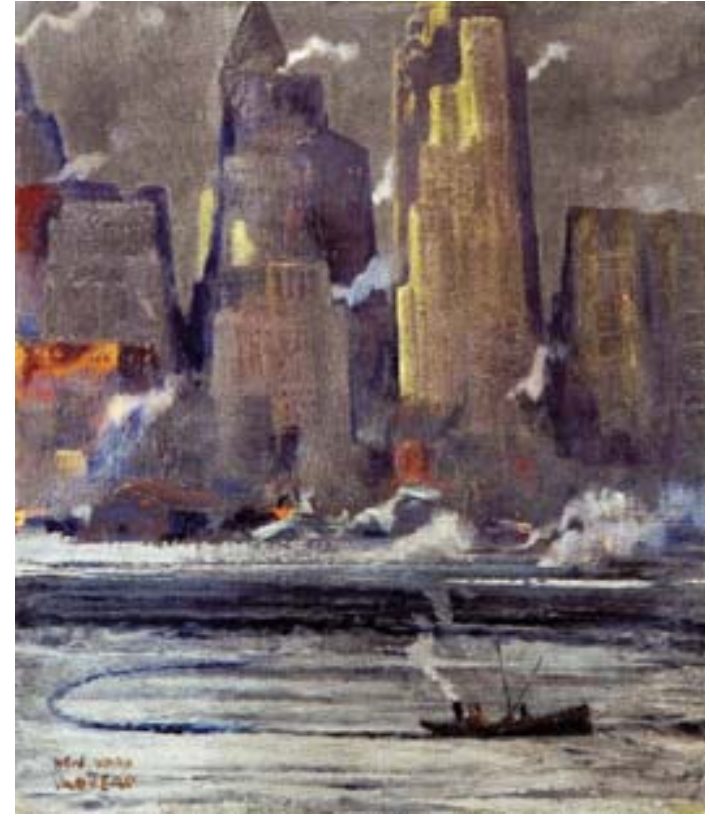

Fig. 3. Joaquín Vaquero, New York, 1928. Óleo sobre tela, $61 \times 50 \mathrm{~cm}$.

Desde allí, Rosa y sus hermanos continuarían su viaje hacia El Salvador para reunirse con los suyos y llevar a cabo los preparativos de la boda.

Después de una travesía de casi dos semanas, el 22 de diciembre entraban en la bahía de Nueva York, con la magnífica perspectiva de los rascacielos de Manhattan al fondo. Una vista que ya desde la cubierta del barco le impacto tremendamente, y que no tardaría en pintar (fig. 3):

(...) Empieza a notarse más movimiento en la tripulación del transatlántico que nos lleva. Las máquinas se detienen para volver enseguida a funcionar. Con una niebla muy densa entramos en los "Narrows". Intento ver los primeros rascacielos pero sólo alcanzo a ver, apenas, algunos barcos pequeños que pasan y vuelven a perderse de vista (...). Un enorme tanque pintado de minio rompe de pronto la sinfonía de grises (...). Casi repentinamente, la niebla se hace negra e inesperadamente en magnífico espectáculo, como inmensos fantasmas, aparecen ante mí los imponentes rascacielos del Down Town. La niebla me reservó la sorpresa de mostrarlos de golpe en toda su magnitud. El barco se detiene antes de atracar y puedo gozar de este espectáculo durante bastante tiempo $(\ldots)^{20}$.

A su llegada a Nueva York se hospedó en Hotel Judson, de la 53 Washington Square, donde pasó las navidades ilusionado con su inminente exposición comprometida para el día siete de enero en aquella ciudad que se le antojaba de un potencial plástico enorme. Pero las ilusiones del joven se vieron truncadas al acudir a recoger sus cuadros al puerto y comprobar que no habían llegado.

${ }^{20}$ AVS. Vaquero Palacios, "Nueva York”, en Escritos diversos, III, s. p. 
El barco que debía traerlos había vaciado su carga y estos no terminaban de aparecer. Vaquero acudía día tras día a la aduana sin resultado alguno, lo que le colocaba en una situación realmente desesperada. La fecha señalada para la inauguración de su exposición en la galería Knoedler pasó, y el joven se encontraba sólo en Nueva York, sin conocer el idioma y sin más recursos que trescientos dólares que había previsto reponer pronto con la venta de cuadros (fig. 4). Para mayor desasosiego, era invierno y la ciudad se hallaba envuelta en un densa niebla y bajo un frío tan intenso que obligaba a picar el hielo de las aceras para hacerlas transitables.

$\mathrm{Su}$ único contacto en aquellos momentos era su paisano y amigo, el pintor Evaristo Valle, que se encontraba pasando una temporada en Nueva York invitado por unos consignatarios de buques de Gijón, los García Díaz, para celebrar allí una exposición. Vaquero le acompañó el 15 de enero en la inauguración de su exposición en una galería de la calle 59 th West $\mathrm{Side}^{21}$. A pesar de la extraordinaria calidad de su obra, la muestra no tuvo ningún éxito al tratarse de una sala alejada del circuito comercial artístico neoyorquino. El día de la inauguración

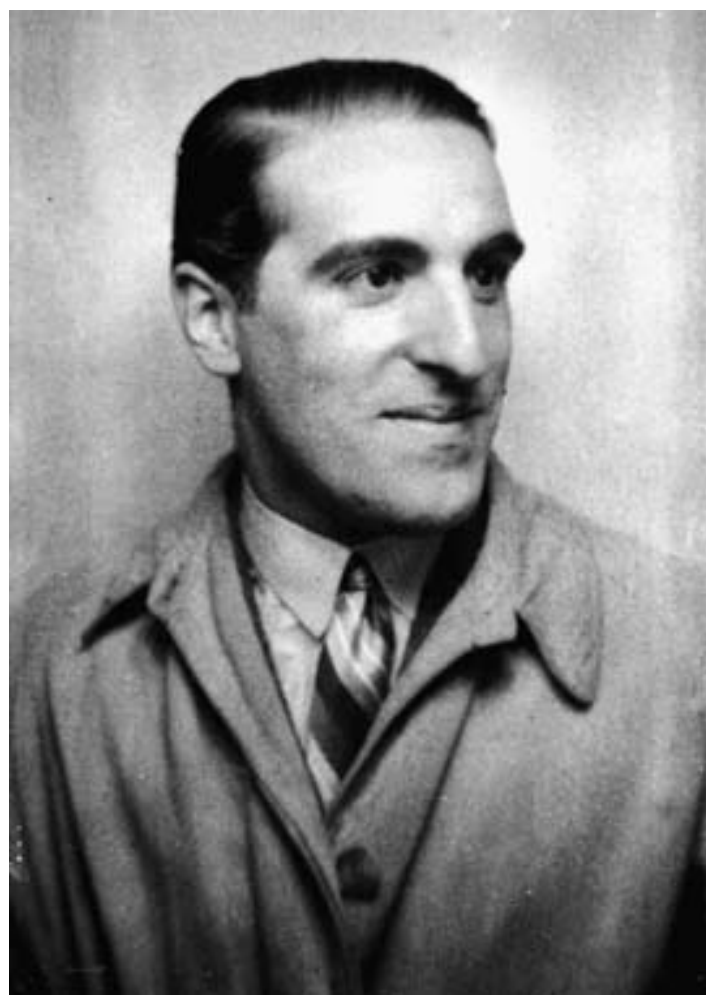

Fig. 4. Joaquín Vaquero a su llegada a Nueva York (diciembre de 1927). se produjo, además, un lamentable accidente: uno de los guitarristas contratados para amenizar el acto cayó fulminado por un ataque cardíaco en plena actuación ${ }^{22}$. Pero a pesar de este y de otros incidentes -como el robo de tres de sus cuadros-, el pintor gijonés mantenía intacta su ilusión y su peculiar sentido del humor ${ }^{23}$.

Con el reducido capital de que disponía, Vaquero alquiló un pequeño estudio perteneciente al escritor Wood Kahler en Greenwich Village (47 Christopher Street), el barrio de los artistas, escritores e intelectuales de Nueva York. Solo, sin cuadros y sin dinero, se vio obligado a buscar toda clase de encargos para sobrevivir. Realizó dibujos para el estampado de tejidos, pinturas de cabeceros de cama para niñas y las ilustraciones de un libro infantil sobre animales de la selva. También pintó algunos decorados de cine para la First National Pictures. Estos se hacían entonces pintándolos sólo en rojo y negro, lo que constituía una experiencia muy interesante ${ }^{24}$.

Casi un mes después de su llegada a Nueva York y gracias a las gestiones realizadas por los mentores del pintor gijonés - los García Díaz-, Vaquero pudo localizar el paradero de sus cuadros. Por un error de embarque en Gijón, habían sido cargados en un barco con destino al puerto de Hamburgo, donde se hallaban a punto de salir a subasta pública al no ser reclamados por nadie.

\footnotetext{
${ }^{21}$ AVS. Vaquero Palacios, Diario 1927-1928 (15-I-1928).

22 CARAntoña, 1986:103.

${ }^{23}$ Declaraciones de Vaquero al autor, Segovia, julio 1989,

24 AVS. Vaquero Palacios, Diario 1927-1928 (3-II-1928 y 6-II-1928).
} 


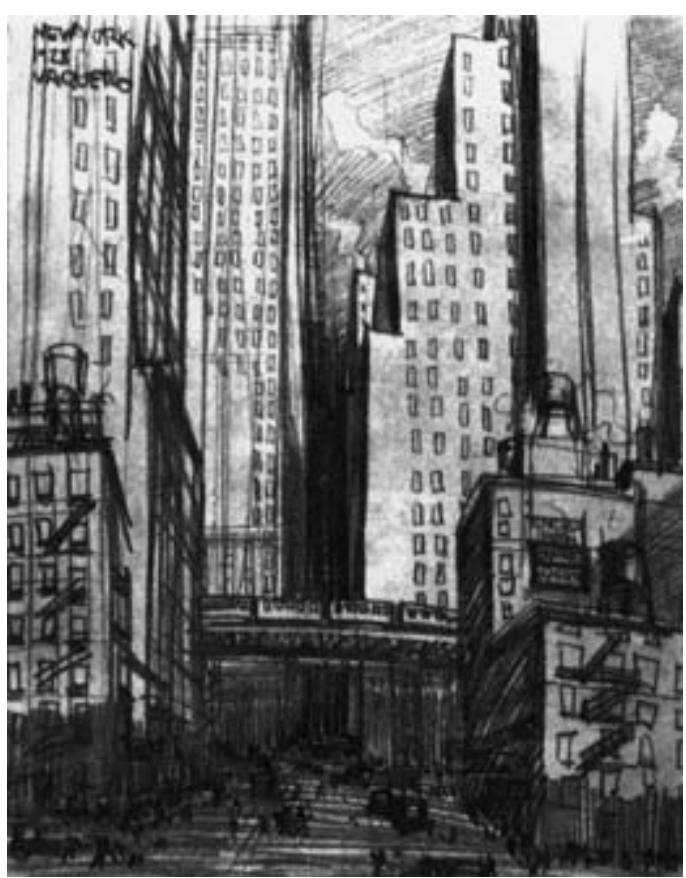

Fig. 5. Joaquín Vaquero, New York, 1928. Dibujo a lápiz sobre papel.

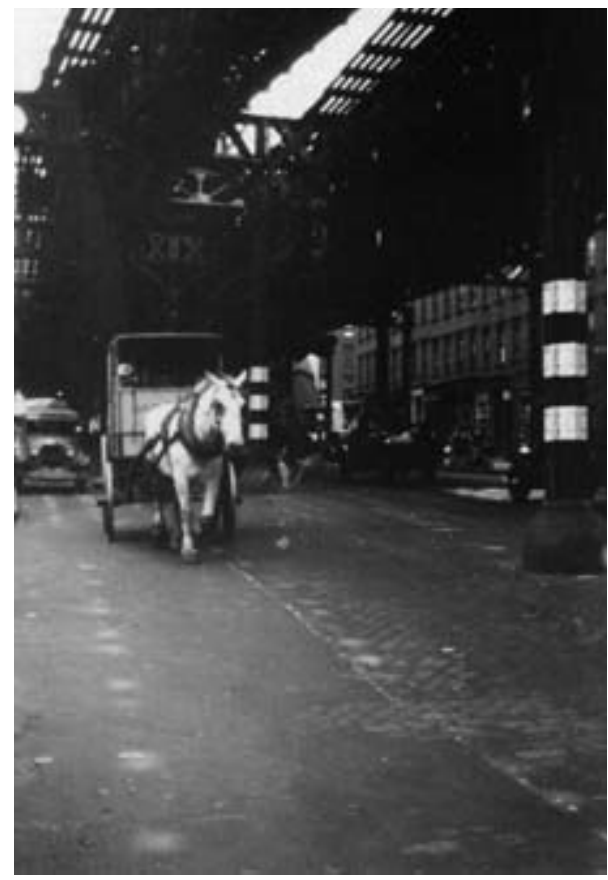

Fig. 6. Nueva York, 1928. Fotografía: Joaquín Vaquero. Archivo Vaquero, Segovia.

Aquella noticia le devolvió la ilusión, pues Mr. Henchel, director de la galería Knoedler, mantenía el compromiso de celebrar su exposición una vez apareciesen los cuadros. Por lo demás, su facilidad de trato y su espíritu abierto y comunicativo le habían granjeado numerosas amistades. Gracias a los contactos que durante su estancia en Nueva Yok en 1922 había establecido un amigo suyo, el también pintor y arquitecto Roberto Fernández Balbuena, conoció al reputado crítico literario del New York Herald Tribune, Herschel Brickell. Vaquero entabló una gran amistad con el escritor y su mujer, Norma, quienes le introdujeron en el ambiente cultural y artístico neoyorkino, frecuentado, entre otros, por el magnate Archer M. Huntington y los pintores Robert Chandler, Edward Hopper y Lyonel Feininger.

A Vaquero le entusiasmó Nueva York como tema pictórico, con sus calles repletas de automóviles y de gentes que van y vienen bajo el ruido intermitente y ensordecedor de los trenes elevados. Por encima de ellas, los imponentes rascacielos se alzaban escalonadamente hasta alturas increíbles. Este perfil tan característico de los rascacielos era una consecuencia de la ley de planificación urbana (Zoning Law) de 1916, que obligaba a su retranqueo en función de la anchura de la calle para permitir así la entrada de luz y aire ${ }^{25}$.

Atraído por aquel espectáculo fascinante, dibujó sus calles y avenidas atestadas de banderas, gentes y vehículos en constante movimiento (fig. 5). En contraste con esta vorágine de la vida moderna, Vaquero se sintió conmovido por aquellos pencos condenados a tirar de pesados carros entre pasarelas elevadas y automóviles de enormes faros circulares como ojos (fig. 6). Pero no sólo

\footnotetext{
${ }^{25}$ WeBer, 1993: 26.
} 
realizó dibujos. También pintó numerosos paisajes urbanos de tonos graves, con sombras muy acusadas, humos y

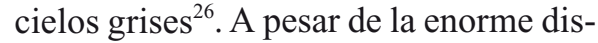
tancia física-como reconoció el artista en más de una ocasión- al pintar Nueva York le venía el recuerdo de las montañas de Asturias, al asemejársele las calles de la ciudad con enormes grietas abiertas en una montaña (fig. 7):

En Down Town, por el tamaño colosal de los edificios, las calles llegan a parecer desfiladeros en las montañas, abiertos por el trabajo constante del torrente que corre en el fondo. En ese torrente oscuro y tumultuoso de gente y automóviles, nunca entra el sol en lo más profundo y la luz, cenital, cae suavemente hasta el fondo de las avenidas ${ }^{27}$.

Por lo demás, su consideración de pensionado por la Junta para Ampliación de Estudios le facilitó el acceso a los estudios y rascacielos en construcción de los arquitectos más activos en aquellos momentos como Raymond Hood, Wi-

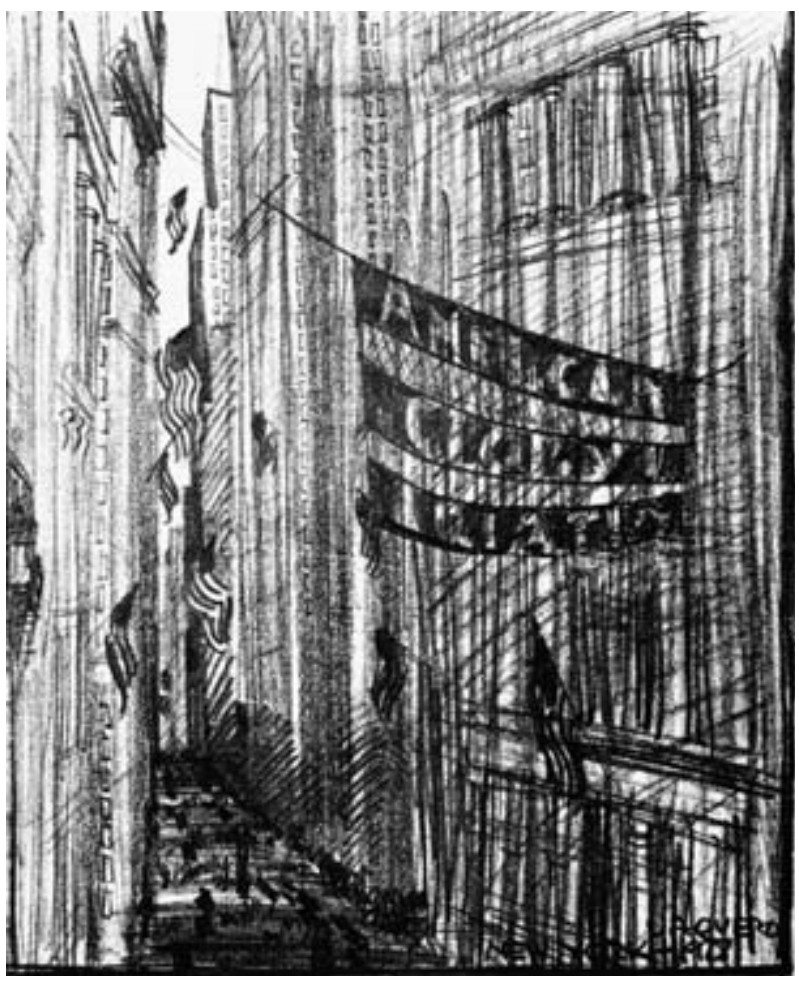

Fig. 7. Joaquín Vaquero, New York, 1928. Dibujo a lápiz sobre papel. lliam van Alen y las firmas Corbett, Harrison \& MacMurray y Shrebe, Lamb \& Harmon ${ }^{28}$.

Si desde un punto de vista pictórico y arquitectónico Nueva York le produjo un fuerte impacto con sus gigantescos rascacielos y sus calles oscuras, a nivel anímico las sensaciones fueron bien distintas. En sus anotaciones personales dejó constancia de la congoja y desazón que le producía la vida en aquella metrópoli deshumanizada:

Tengo la sensación, la conciencia de hallarme en el centro del mundo con todas las posibilidades a mi alcance, pero sin poder alcanzarlas por mi infinita pequeñez. Una sensación de inmensa soledad. La evidencia de no ser nadie y la lucha por abrirme paso entre la multitud. Esperanza y desesperanza. Prisa e inquietud ${ }^{29}$.

Transcurrido más de un mes de su llegada a Nueva York, el 10 de febrero recuperó sus cuadros en la aduana después de una serie de trámites bastante pintorescos ${ }^{30}$. Enterado de ello, el director de la galería Knoedler realizó un reajuste en su calendario de exposiciones para dar cabida a la suya, fijando la fecha de la inauguración para el mes de marzo.

\footnotetext{
${ }^{26}$ Gómez SAntos, 1974: 177.

27 AVS. Vaquero Palacios, "Nueva York", en Escritos temas diversos, III, s. p.

${ }^{28}$ Pérez Lastra, 1992: 26.

29 AVS. Vaquero Palacios, "Nueva York", en Escritos temas diversos, III, s. p.

30 AVS. Vaquero Palacios, Diario 1927-1928 (10-II-1928)
} 
Durante este tiempo tuvo mucha relación con su paisano Evaristo Valle, quien le dejó algunos marcos para su exposición antes de embarcarse el 23 de febrero rumbo a La Habana ${ }^{31}$. A través de sus contactos en la gran ciudad, Vaquero recibió la invitación para celebrar una exposición individual en un club de arte: The Three Arts Club ${ }^{32}$. La muestra, inaugurada el 26 de febrero, alcanzó un notable éxito de público y de ventas. Poco después concurrió como invitado con tres obras a la 103rd Annual Exhibition of Design en la Gallery of the American Fine Arts Society, ubicada en la 215 W. 57 th $\mathrm{St}^{33}$.

Su exposición en la galería Knoedler (14 East 57th Street) se inauguró el 26 de marzo, coincidiendo con una de grabados de Durero, conmemorativa del cuarto centenario de su muerte, y otra de acuarelas de Rodin que ocuparon simultáneamente las otras dos salas de la galería (fig. 8). Este insólito acompañamiento parecía augurar un éxito seguro, como así resultó ser. El Museo de Brooklyn adquirió un cuadro suyo, Iglesia de San Andrés-Madrid-, que incorporó a su sección de pintura española. Por su parte, el pintor simbolista Arthur Bowen Davies, presidente de la Asociación de Pintores y Escultores Americanos, le compró un cuadro (Hospital de Órbigo, León). Además, le invitó a su estudio donde le mostró su obra y le obsequió tres de sus grabados ${ }^{34}$.

La prensa neoyorquina, por lo demás, se hizo amplio eco de la exposición del joven pintor español, alabando en sus paisajes asturianos y castellanos la claridad compositiva y su colorido cálido y vibrante ${ }^{35}$. Buena muestra de ello es la crítica que le dedicó Deoch Fulton en las páginas de The Art News:

Sus conocimientos de arquitectura han determinado en él una apreciación de forma y estructura cuya influencia en cuadros de paisajes y casas es absolutamente evidente, al estar firmemente dibujadas caracterizando fuertemente sus cuadros. Sus lienzos están sólidamente construidos dentro de la más fina estructura (...). Y su color es delicioso, de pinceladas asombrosamente amplias. Algunos cuadros son brillantes, llenos de amarillos calientes, de azules metálicos y de bermellón; otros tienen el suave brillo de los tejidos antiguos; y otros reproducen la luz nebulosa que reflejan las viejas murallas $(\ldots)^{36}$.

Pero no sólo los periódicos neoyorquinos reseñaron la exposición. También algunas revistas del Viejo Continente, como la londinense $\mathrm{Apolo}^{37}$, se ocuparon ampliamente de ella. Cabe conjeturar que detrás de esta maniobra se hallaría su amigo Muirhead Bone, quien desde Oxford seguía con interés los pasos del joven español en la gran metrópoli.

Arregladas las cuentas en la galería Knoedler, su director le entregó una carta para The Veerhoff Galleries de Washington, por si le interesara mostrar allí su obra. La posibilidad de exponer en Washington le proporcionó el pretexto para abandonar el ajetreo de Nueva York, una ciudad que comenzaba a hastiarle ${ }^{38}$.

Estando en Washington tuvo noticia de la inminente convocatoria por parte de la Unión Panamericana de un concurso mundial de arquitectos para erigir un faro monumental a la memoria de Cristóbal Colón en Santo Domingo, la primera tierra que tocó el navegante en el Nuevo Mundo.

31 AVS. Vaquero Palacios, Diario 1927-1928 (13-II-1928; 16-II-1928 y 23-II-1928).

32 AVS. Vaquero Palacios, Diario 1927-1928 (26-II-1928).

33 AVS. Vaquero Palacios, Diario 1927-1928 (16-III-1928).

34 AVS. Vaquero Palacios, Diario 1927-1928 (2-IV-1928 y 3-IV-1928).

${ }^{35}$ Herald Tribune, 25-III-1928; New York Evening Post, 31-III-1928; New York American, 1-IV-1928; Palmer, 1928; Pearson, 1928.

${ }^{36}$ Fulton, 1928.

37 STEPHENS, 1930

38 AVS. Vaquero Palacios, Diario 1927-1928 (12-IV-1928 y 15-IV-1928). 


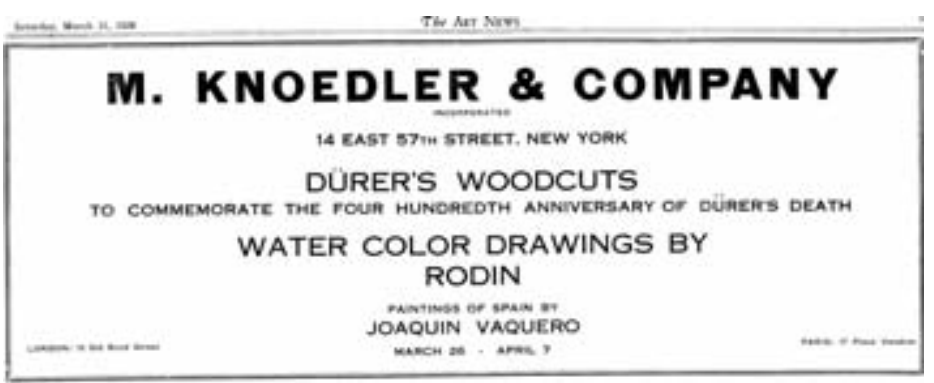

Fig. 8. Anuncio de su exposición en la galería Knoedler publicado en The Art News (31-III-1928).

Fascinado por la idea, se puso en contacto con el Director General de la Unión Panamericana, Leo S. Rowe, para solicitar información sobre el concurso, quien se comprometió a hacerle llegar el libro de bases una vez hubiera concluido su redacción ${ }^{39}$.

$\mathrm{Su}$ exposición en la Veerhoff Galleries (1512 Connecticut Avenue) se inauguró el 14 de mayo bajo el patronato del embajador de España en Washington, don Alejandro Padilla (fig. 9). Al acto acudieron numerosos embajadores hispanoamericanos y otras personalidades, entre ellas el vizconde de Güell, destacado literato ${ }^{40}$. Con motivo de la inauguración, Alexander Kirk, embajador de Estados Unidos en China y coleccionista compulsivo de arte oriental, organizó una fiesta en honor del pintor español en su espléndida mansión, auténtico alarde de sofisticación ${ }^{41}$.

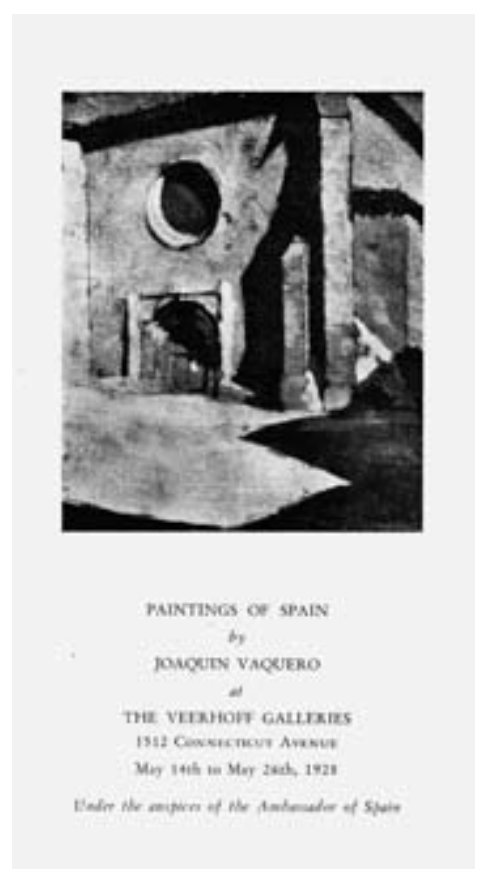

Fig. 9. Portada del díptico editado con motivo de su exposición en The Veerhooff Galleries.

\section{La "huída" de Nueva York y el descubrimiento del Caribe}

Saturado de aquella vida trepidante, en mitad de la fiesta y sin avisar a nadie, Vaquero abandonó precipitadamente la casa de su anfitrión y se dirigió a su hotel para recoger sus cosas y tomar un tren de medianoche a Nueva York, decidido a embarcarse allí en el primer barco que partiese hacia Centroamérica ${ }^{42}$. Sus nervios comenzaban a no soportar por más tiempo el ritmo frenético de Nueva York, aquella inmensa ciudad de más de siete millones de habitantes en la que llevaba cinco meses luchando por salir adelante. Además, su prometida le aguardaba en San Salvador para celebrar su enlace matrimonial. Por la mañana adquirió en una de las compañías de navegación de Battery Place un pasaje para un buque que zarpaba hacia Jamaica ese mismo día. Desde la cubierta del barco que le llevaba a Jamaica, Vaquero contempló reconfortado la imagen de la ciudad hundiéndose entre las olas del mar. A continuación envió telegramas a Alexander Kirk, al director de la

39 AVS. Vaquero Palacios, Diario 1927-1928 (18-IV-1928; 19-IV-1928; 20-IV-1928; 3-V-1928; 4-V-1928 y 5 V-1928).

40 Washington Star, 27-V-1928.

${ }^{41}$ GARCía, 1966.

42 Martínez de Rivas, 1966: 20. 


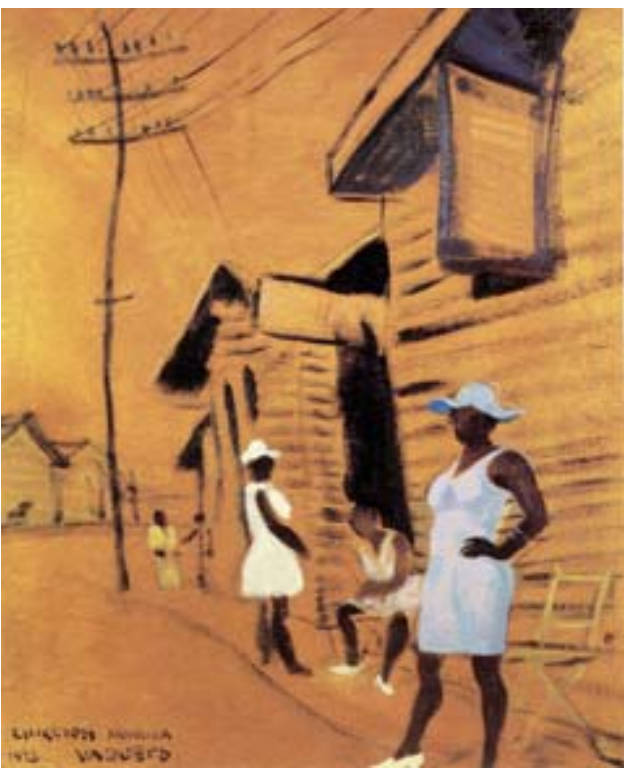

Fig. 10. Joaquín Vaquero, Burdeles en Kingston, 1928. Óleo sobre tablero de cedro, 46 x $38 \mathrm{~cm}$. galería y al resto de amigos que tan calurosamente le habían acogido para excusarse por su precipitada "huída" y comunicarles su paradero, lo que lejos de enojarles les pareció algo maravilloso ${ }^{43}$.

A la espera de enlazar con otro barco hacia Centroamérica, Vaquero se estableció temporalmente en Kingston, donde plasmó los suburbios de la ciudad dibujándolos a pincel sobre el soporte desnudo de la madera (fig. 10). Pasadas unas semanas se embarcó hacia Puerto Barrios (Guatemala), desde donde continuó su viaje en tren hasta San Salvador. Durante su estancia de casi dos meses en El Salvador pintó los volcanes, las selvas y las viejas iglesias coloniales ${ }^{44}$. Tras su boda, celebrada el 5 de agosto, el matrimonio abandonó San Salvador para iniciar un viaje de novios por el Pacífico, Panamá, Colombia, las Antillas y Cuba, aprovechando su estancia en estos países para pintar (fig. 11).

A principios de septiembre regresaron a los Estados Unidos para recoger los cuadros de la exposición que había dejado colgada en Washington cuan-

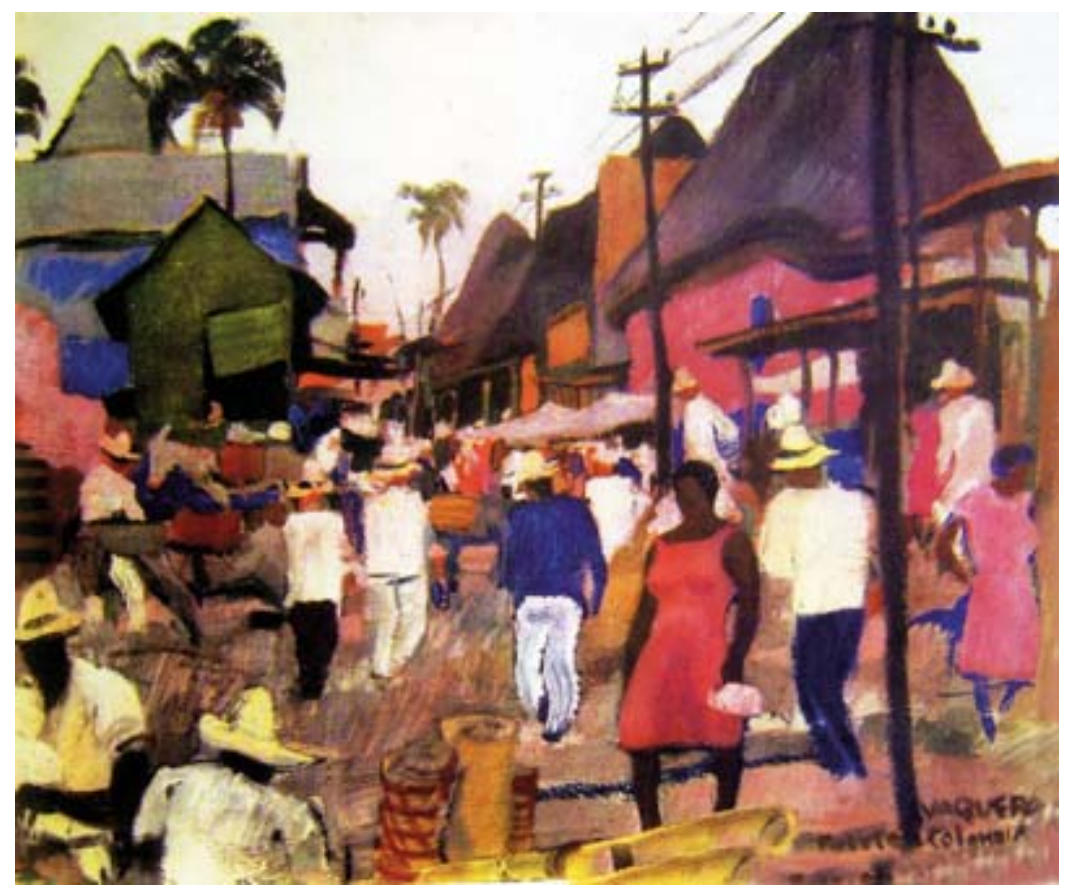

Fig. 11. Joaquín Vaquero, Mercado en Puerto Colombia, 1928. Óleo sobre cartón, 38 x 46 cm.

43 Declaraciones del artista, recogidas en García, 1966.

${ }^{44}$ LÓPEZ PINEDA, 1928. 
do partió precipitadamente hacia Jamaica. Allí se enteró de que el 1 de septiembre había quedado abierto el plazo de inscripción para el Concurso del Faro de Colón. Decidido a tomar parte en él, telegrafío a su amigo y compañero de promoción en la Escuela de Arquitectura de Madrid Luis Moya proponiéndole formar equipo. Cerrado el acuerdo entre ambos, llevó a cabo su inscripción en la propia sede de la Unión Panamericana de Washington con el número once ${ }^{45}$.

\section{El retorno a la gran metrópoli: la aventura del Faro de Colón (1930)}

Dando por concluida su estancia en América, Vaquero regresó en septiembre de 1928 a Madrid donde inició junto a Luis Moya el anteproyecto para el Faro de Colón. La Unión Panamericana había establecido que el concurso se desarrollaría en dos etapas. La primera, en Madrid, se encargaría de seleccionar diez anteproyectos cuyos autores volverían a competir en una segunda fase a celebrar en una ciudad latinoamericana a determinar en su momento, en la que se decidiría el proyecto vencedor ${ }^{46}$.

Las bases del concurso, redactadas por el arquitecto norteamericano Albert Kelsey ${ }^{47}$, especificaban la altura máxima del monumento -600 pies-, los materiales de construcción -cemento armado sobre esqueleto de acero- así como la incorporación de por lo menos una gran linterna giratoria. El programa prescribía la inclusión dentro del Faro de una capilla a la que se trasladaría desde la catedral de Santo Domingo el sepulcro neogótico que albergaba los supuestos restos de Colón, un museo, una biblioteca y una sala de conferencias. Pero el monumento-faro no constituiría sino la unidad principal de una extensa ciudad denominada Parque Panamericano que debía trazarse sobre un vasto terreno de mil hectáreas situado en la margen izquierda de la ría del Ozama, frontero a la ciudad histórica de Santo Domingo. Sobre este terreno lindante con el mar, los competidores debían proyectar un gran aeródromo, un mástil de amarre para dirigibles, un embarcadero y un puerto monumentales, una ciudad nueva destinada a residencias privadas y, finalmente, un puente de enlace de estas nuevas construcciones con la antigua ciudad de Santo Domingo ${ }^{48}$. Se trataba, pues, de un macroproyecto destinado a convertir esa punta antillana en el nudo de las comunicaciones marítimas y aéreas del continente americano.

Habida cuenta de que en el concurso preliminar lo esencial era encontrar un símbolo del acontecimiento histórico, los dibujos presentados se limitaban a la unidad principal -el monumentofaro-, quedando reservado el desarrollo completo del programa y las consideraciones de orden práctico para los competidores que pasaran a la fase final. Siguiendo las premisas del concurso, que buscaba para el monumento un simbolismo panamericanista de fácil lectura que tuviese presentes las tres civilizaciones americanas -la indígena, la colonial y la moderna ${ }^{49}$-, Vaquero y Moya fusionaron en su diseño las formas de la pirámide maya y del rascacielos neoyorquino ${ }^{50}$, la expresión más completa del art déco americano de los años veinte. El motivo decorativo fundamental de esta pirámide-rascacielos lo constituía una gigantesca figura de Colón lo bastante estilizada como para fundirse con la masa arquitectónica general ${ }^{51}$. Las portadas de acceso incorporaban una profusa decoración en relieve inspirada en motivos aztecas y mayas, que contrastaba con la simplificación geométrica y la desnudez de las masas del monumento (fig. 12).

\footnotetext{
45 Vaquero Palacios, 1990: 26.

${ }^{46}$ Para una síntesis sobre el desarrollo de este concurso, v. Acosta y Lara, 1949, y Egaña Casariego, 2010: 158-177.

${ }^{47}$ Kelsey, 1928.

48 Kelsey, 1928: 18; Almenar, 1929.

${ }^{49}$ Kelsey, 1928: 5.

${ }^{50}$ CAPITEL, 1998:12

51 AVS. Vaquero Palacios y Moya Blanco, 1931b: 2 y 4.
} 


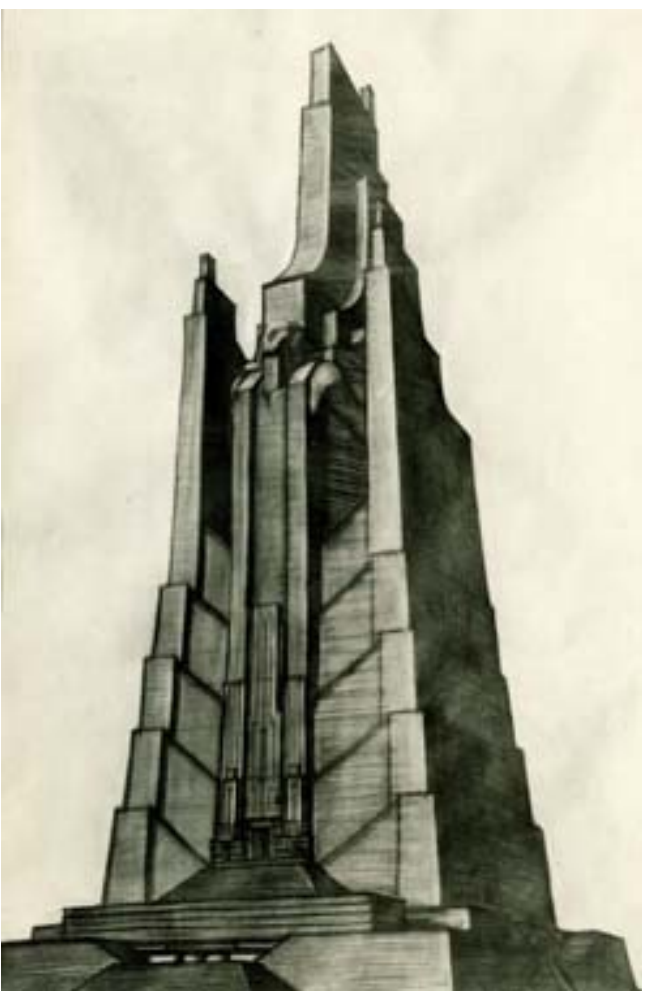

Fig. 12. Joaquín Vaquero y Luis Moya, Anteproyecto para el Faro de Colón, 1929. Perspectiva. Archivo Vaquero, Segovia.
Auspiciado por las veintiuna repúblicas americanas, el concurso alcanzó un éxito sin precedentes, inscribiéndose 1.926 arquitectos procedentes de 48 países que presentaron un total de 455 anteproyectos en la primera fase celebrada en 1929 en Madrid $^{52}$. La exposición de los dibujos quedó inaugurada el 27 de abril en el Palacio de Cristal del Retiro $^{53}$ (fig. 13), tras lo cual el jurado internacional de arquitectos formado por el norteamericano Raymond Hood, el finlandés Eliel Saarinen y el uruguayo Horacio Acosta y Lara dio a conocer los nombres de los autores de los diez anteproyectos seleccionados para concurrir a la segunda fase del concurso ${ }^{54}$. Entre ellos se hallaba el de Vaquero y Moya, con la particularidad de resultar no sólo el único español seleccionado sino también el único de habla hispana, lo que les valió al respaldo unánime de la prensa nacional ${ }^{55}$.

La magnitud y complejidad del programa a desarrollar, unido a su interés por conocer los modernos sistemas de construcción y las ruinas precolombinas, les animó a emprender un largo viaje de estudio por Estados Unidos y México, subvencionado en parte por el Ministerio de Instrucción Pública y Bellas Artes ${ }^{56}$.

La aventura se inició el 15 de agosto de 1930 en el puerto de Gijón, donde se embarcaron en el vapor Buenos Aires rumbo a La Habana, para pasar desde allí a Miami ${ }^{57}$. Junto a ellos viajó también la esposa de Vaquero, Rosa Turcios. La necesidad de

52 "Datos sobre el Concurso para la construcción del faro de Colón en la isla de Santo Domingo", Patria, San Salvador, 15-XI-1930.

53 "En el Retiro. Exposición de proyectos para el faro de Colón", Heraldo de Madrid, 27-IV-1929; "El Presidente del Consejo inaugura la Exposición de Proyectos para la construcción del faro de Colón en la isla de Santo Domingo", La Nación, Buenos Aires, 27-IV-1929; "Exposición de proyectos del faro a Colón. Ayer quedó inaugurada en el Retiro con la asistencia del jefe del Gobierno y del Cuerpo diplomático", El Debate, Madrid, 28-IV-1929; "Exposición de proyectos para el Faro de Colón", $A B C$, Madrid, 28-IV-1929; "La exposición de proyectos para el faro de Colón, en la República de Santo Domingo ha sido inaugurada", Informaciones, Madrid, 30-IV-1929; "El Faro monumental de Colón en Santo Domingo", $A B C$, Madrid, 30-V-1929.

${ }^{54}$ En su número extraordinario dedicado al Faro de Colón, la revista Arquitectura reprodujo el informe del jurado así como los diez anteproyectos seleccionados, los distinguidos con mención honorífica y algunos otros. Arquitectura, 121 (1929).

${ }^{55}$ FRANCO DE ESPES, 1930. Numerosos periódicos y revistas de la época reprodujeron el anteproyecto español, al tiempo que alentaban a sus jóvenes autores con sus felicitaciones y esperanzas de triunfo. La Construcción moderna, n. $^{\circ}$ 12, Madrid, 30-VI-1929; La Época, Madrid, 27-III-1930; Vida marítima, 30-III-1929; El Sol, Madrid, 27-III-1930.

${ }^{56}$ Este insólito viaje de estudios nos es conocido en sus detalles a través de la Memoria presentada a su vuelta ante el Ministerio de Instrucción Pública y Bellas Artes. AVS. Vaquero Palacios y Moya Blanco, 1931a; Egaña Casariego, 2011: 91-103.

57 AVS. Vaquero Palacios y Moya Blanco, 1931a: 1. 


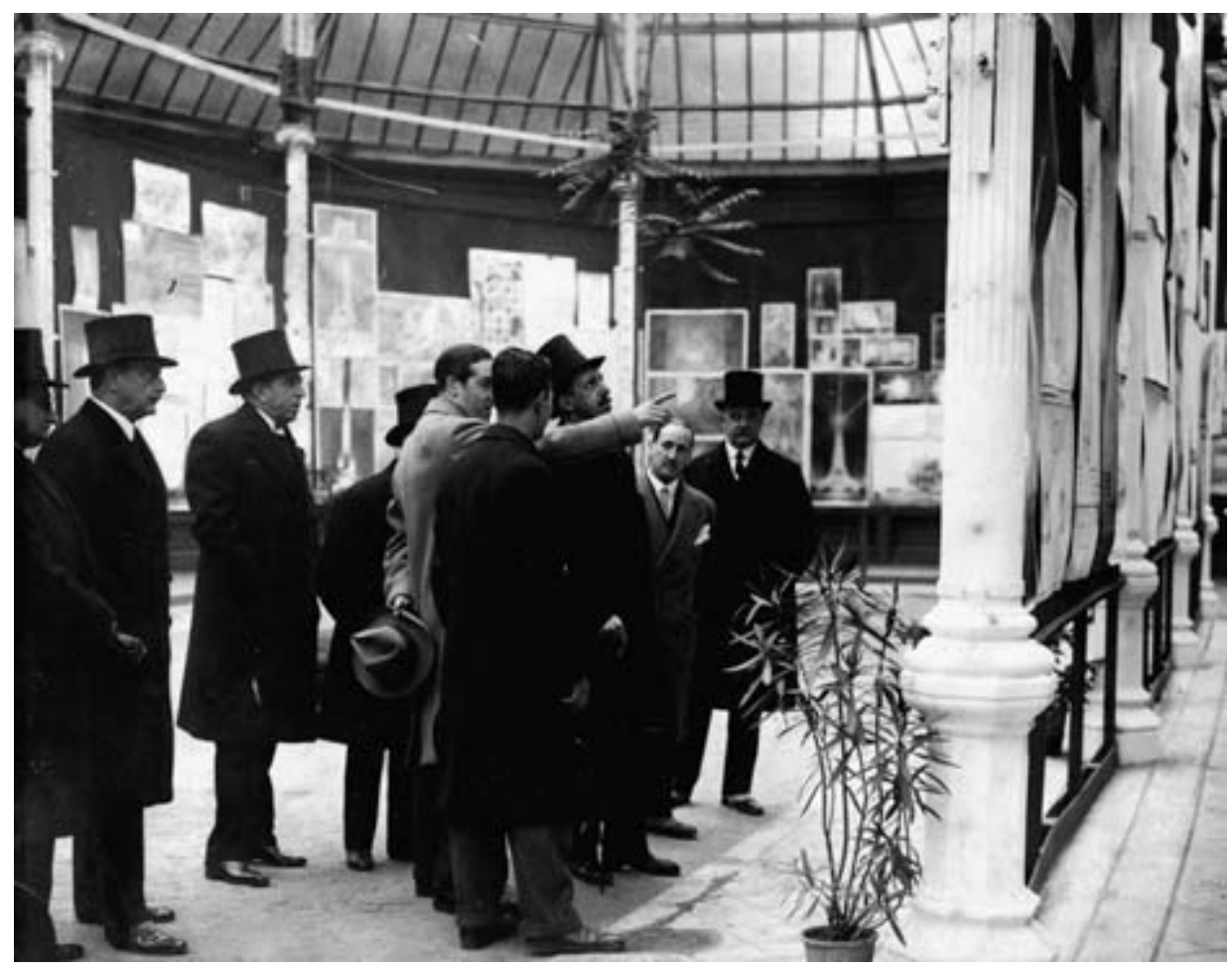

Fig. 13. Visita del rey Alfonso XIII a la exposición de anteproyectos para el Concurso del Faro de Colón en el Palacio de Cristal. Madrid, abril de 1929. De izquierda a derecha: Tulio M. Cestero (embajador de la República Dominicana); embajador de los Estados Unidos; Cristóbal Colón (duque de Veragua); Sr. Callejo (Ministro de Instrucción Pública y Bellas Artes); Joaquín Vaquero (señalando su proyecto); Luis Moya; Alfonso XIII; César de la Torre Trassierra (arquitecto) y Albert Kelsey (Consejero Técnico del Concurso). Archivo Vaquero, Segovia.

conocer rascacielos, faros, museos, aeropuertos y puentes que pudieran servirles de ayuda para proyectar las diferentes unidades que contemplaba el programa, les llevó a visitar algunas de las principales ciudades de Estados Unidos.

El recorrido se inició en Nueva York, a donde llegaron el 9 de septiembre. De especial provecho les resultó el estudio de los sistemas de construcción de los últimos rascacielos, que Vaquero había tenido ocasión de admirar ya en su anterior estancia en los Estados Unidos. En esta ocasión, y recomendados por el International Institute of Education, visitaron, entre otros edificios, el Chrysler, el Empire State, el Chanin, el Manhattan Bank, el Lincoln Hotel, el Medical Center, el Waldorf Astoria y el Daily News ${ }^{58}$, este último proyectado por Raymond Hood, uno de los miembros del jurado internacional que les había seleccionado para la fase final del concurso.

En el Chrysler Building, concluido ese mismo año en la esquina de la calle 42 con la Avenida Lexington, estudiaron con especial interés los revestimientos exteriores metálicos a base de aleaciones de acero, cromo y niquel. A pesar de que el "crack" de 1929 había detenido bruscamente la fiebre constructora de los años de bonanza, uno de los edificios más emblemáticos de Manhattan,

58 AVS. Vaquero Palacios y Moya Blanco, 1931a: 2. 
el Empire State Building, continuaba imparable su ascenso al vertiginoso ritmo de cuatro pisos y medio por semana. La feliz circunstancia de encontrarse aún sin terminar, les dio ocasión de conocer el novedoso sistema de fachadas a base de delgadas tiras de piedra entre bastidores metálicos, que servían para la sujeción de los cercos de las ventanas y permitían la construcción en seco de la envoltura del edificio ${ }^{59}$. Por lo demás, el hecho de hallarse en construcción les facilitó el estudio de la eficaz planificación de los trabajos que, a partir de elementos prefabricados, posibilitaba levantar de forma rápida y fácil aquel gigante en la Quinta Avenida, aspecto a tener muy en cuenta en el caso de resultar vencedores del Concurso:

Debido a sus enormes dimensiones (400 m de altura) la organización de los trabajos ha sido mucho más perfecta que en ningún otro edificio anterior. Para dar una idea de esta organización citaremos el hecho de que antes de ser comenzados los trabajos se habían confeccionado tablas en las que se determinaba el momento exacto en que había de ser colocada cada pieza de la estructura metálica del edificio. Paralelamente a esto se habían estudiado los tendidos de todas las redes de electricidad, calefacción, etc., de manera que definiendo de antemano el momento en que debería trabajarse cada parte del edificio pudieran acoplarse los trabajos de tal modo que en ningún momento pudieran producirse entorpecimientos en ningún lugar de la obra. Debido a la unificación de todos los elementos empleados en la obra, ha sido posible fabricar estos en grandes cantidades, no solamente antes de empezarse a construir el edificio, sino aún antes de estar definido el proyecto, por lo que se comprende lo que facilita los trabajos el tener preparados enormes depósitos de ventanas, puertas, placas de piedra, etc., completamente terminados y dispuestos a ser empleados en cualquier lugar de la obra ${ }^{60}$.

Estando en Nueva York tuvieron noticia del terrible ciclón que devastó la ciudad de Santo Domingo, lo que les condujo a estudiar con especial detenimiento los sistemas de defensa de estas gigantescas estructuras frente a las catástrofes naturales. Pero más allá de estas y de otras consideraciones prácticas, de inmediata aplicación en su proyecto, Vaquero y Moya quedaron fascinados por el espectáculo magnífico de sus siluetas escalonadas recortándose contra el cielo de Manhattan. Una incitación al dibujo y a la pintura que desarrollaron juntos durante el tiempo que permanecieron en la ciudad ${ }^{61}$ (fig. 14).

La ley de planificación urbana de Nueva York había promovido un tipo de arquitectura cubista regida por el principio piramidal que encontró su mejor intérprete en Hugh Ferriss ${ }^{62}$. Este arquitecto norteamericano había renunciado a la práctica profesional para colaborar con los arquitectos más relevantes del momento, adaptando sus proyectos a las prescripciones de la Zoning Law y diseñando el aspecto exterior de sus rascacielos. Su influyente libro The Metropolis of Tomorrow (1929), que Vaquero adquirió en ese momento, mostraba una ciudad de extraordinaria plasticidad bajo cuya fisonomía quedaba entreverada la pirámide maya en una suerte de panamericanismo ${ }^{63}$ que no pasó inadvertido a los jóvenes arquitectos (fig. 15). En plena edad de oro de la literatura sobre los rascacielos, resultaron muy frecuentes las metáforas que identificaban la isla de Manhattan con una nueva Babilonia dominada por estos zigurats modernos (fig. 16), cuyas terrazas en disminución transformaba Ferriss en jardines colgantes, piscinas y campos de golf aéreos ${ }^{64}$.

\footnotetext{
59 AVS. Vaquero Palacios y Moya Blanco, 1931a: 2-3.

${ }^{60}$ AVS. Vaquero Palacios y Moya Blanco, 1931a: 3.

${ }^{61}$ Egaña Casariego, 2010: 165-166. Sobre los dibujos realizados por Luis Moya en América, v. García-GutiÉRrez Mosteiro, 1993: 259-260, y GonzÁlez Capitel y García-Gutiérrez Mosteiro, 2000: 15-19, 34 y 100-101.

${ }^{62}$ Sobre la obra de este singular dibujante, v. Subirats, 1992.

${ }^{63}$ Hughes, 2001: 419.

${ }^{64}$ Conrad, 1984: 258 y ss; Subirats, 1992: 35-38 y 47.
} 


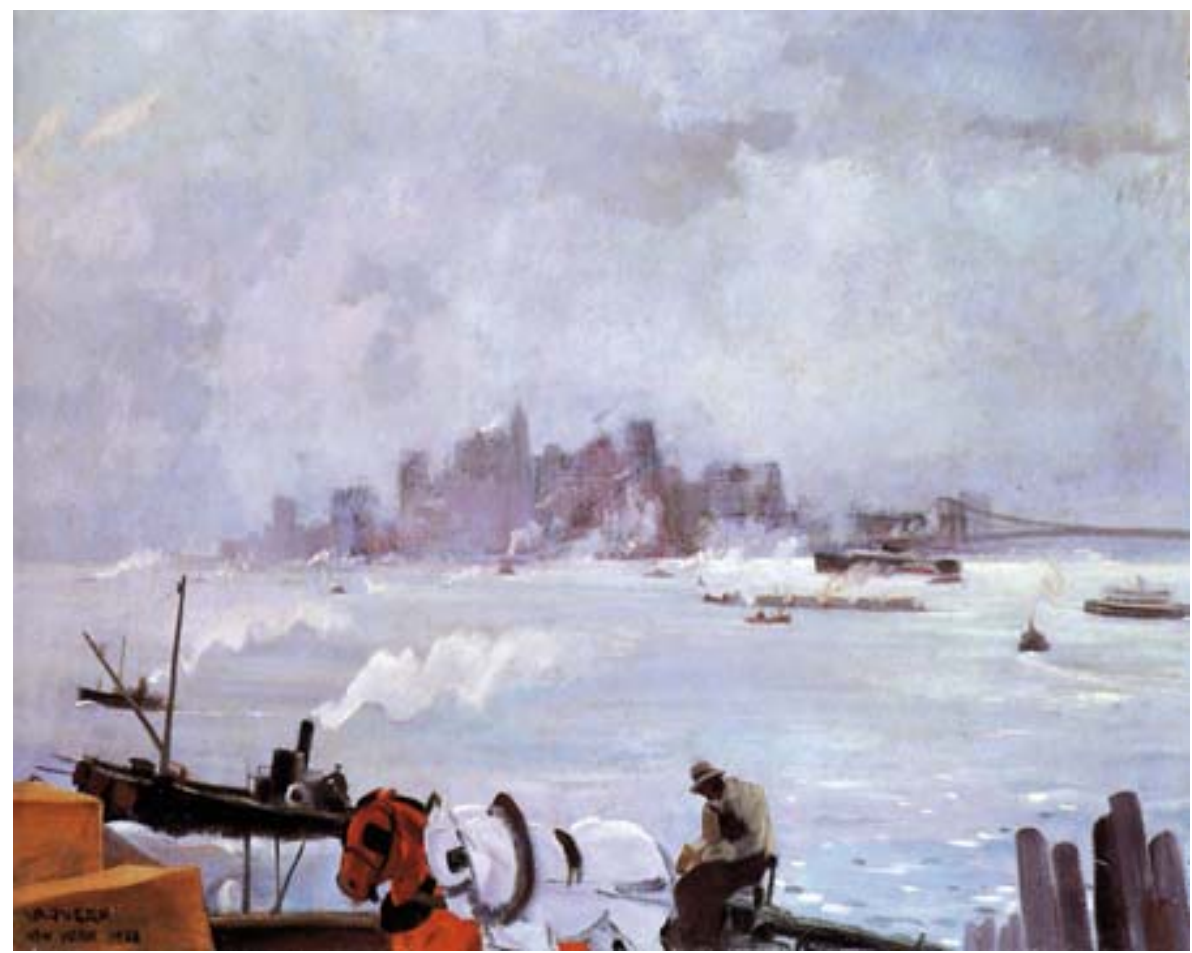

Fig. 14. Joaquín Vaquero, New York, 1930. Óleo sobre tela, 100,5 x 125,7 cm. Col. Argentaria (Madrid).

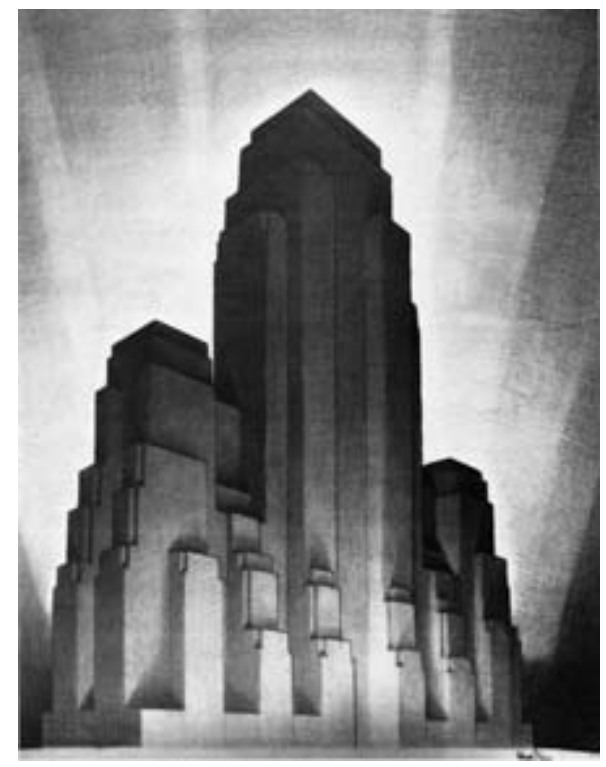

Fig. 15. Hugh Ferris: Tercera fase en la evolución de los edificios retranqueados, 1922 (H. Ferriss, The Metropolis of Tomorrow, Nueva York, 1929).

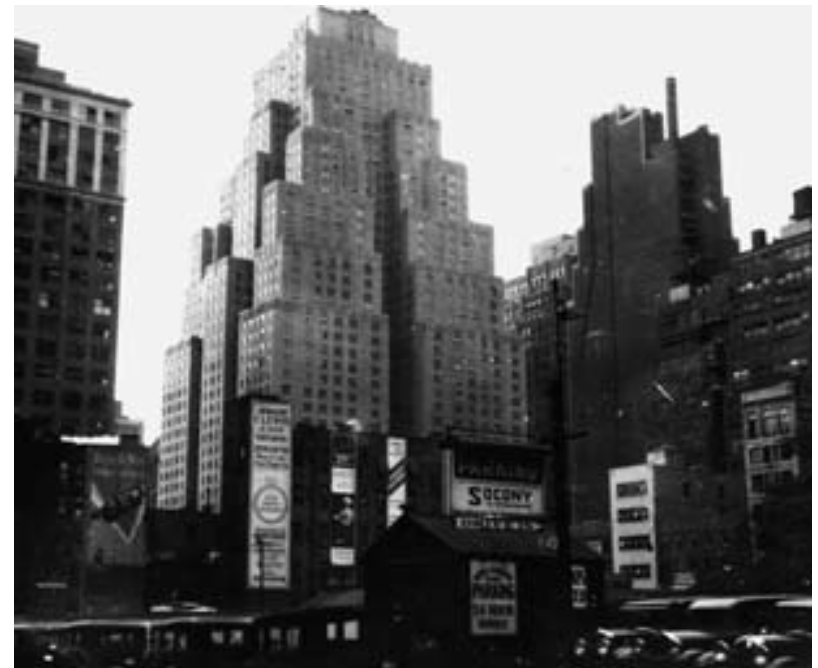

Fig. 16. Times Square, Nueva York (septiembre de 1930). Fotografía: Joaquín Vaquero. Archivo Vaquero, Segovia.

Arch. esp. arte, LXXXVI, 343, JULIO-SEPTIEMBRE 2013, 237-262, ISSN: 0004-0428 

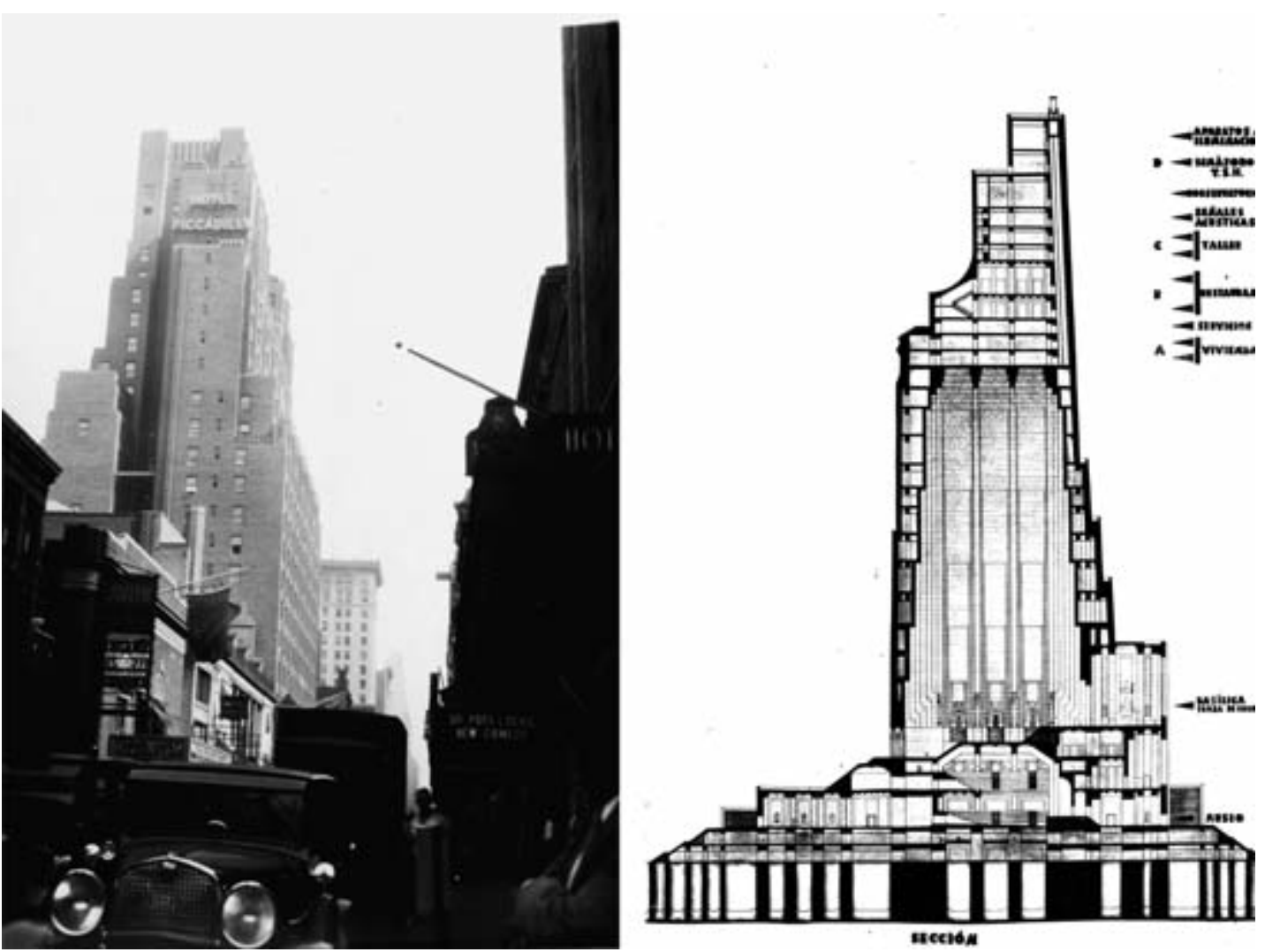

Fig. 17. Hotel Picadilly (West 45th Street), Nueva York, septiembre de 1930. Fotografía: Joaquín Vaquero. Joaquín Vaquero y Luis Moya, Proyecto para el Faro de Colón, 1931. Sección. Archivo Vaquero, Segovia.

Todas estas ideas, de amplia difusión en el ambiente neoyorquino de la época, rondaban la mente del Consejero Técnico del Concurso, quien a propósito de la imagen nocturna que debería mostrar el Faro sugirió, precisamente, una "visión inspirada por un Broadway babilónico" ". Su influencia en el proyecto para el Faro de Colón de Vaquero y Moya quedará patente no sólo en el escalonamiento de sus potentes volúmenes en altura sino también en la ubicación de un restaurante en una de sus terrazas superiores, haciendo realidad una de las fantasías de Hugh Ferriss ${ }^{66}$ (fig. 17).

Durante la breve estancia de los jóvenes arquitectos en la ciudad de los rascacielos -poco más de diez días-, Vaquero recibió el inesperado encargo de ilustrar con sus dibujos la edición norteamericana e inglesa del libro New York, del escritor y diplomático francés Paul Morand, que había concluido el año anterior. La edición corría a cargó de la Henry Holt and Company, una editorial de gran prestigio en los países de habla inglesa. A pesar de lo que se ha escrito y afirmado, no parece probable que Vaquero llegara a conocer personalmente al escritor y trotamundos francés. Y ello, por-

${ }^{65}$ Kelsey, 1928: 63. Sobre el tema de la metáfora babélica que planeaba sobre la arquitectura norteamericana del momento, v. TAFURI, 1984: 210-230.

66 “'Y acaso no podríamos imaginar por un instante -se llegó a interrogar Ferriss- una serie de zigurats provistos de restaurantes y teatros en sus niveles ascendentes?”, cit. en SUBIRATs, 1992: 35. 


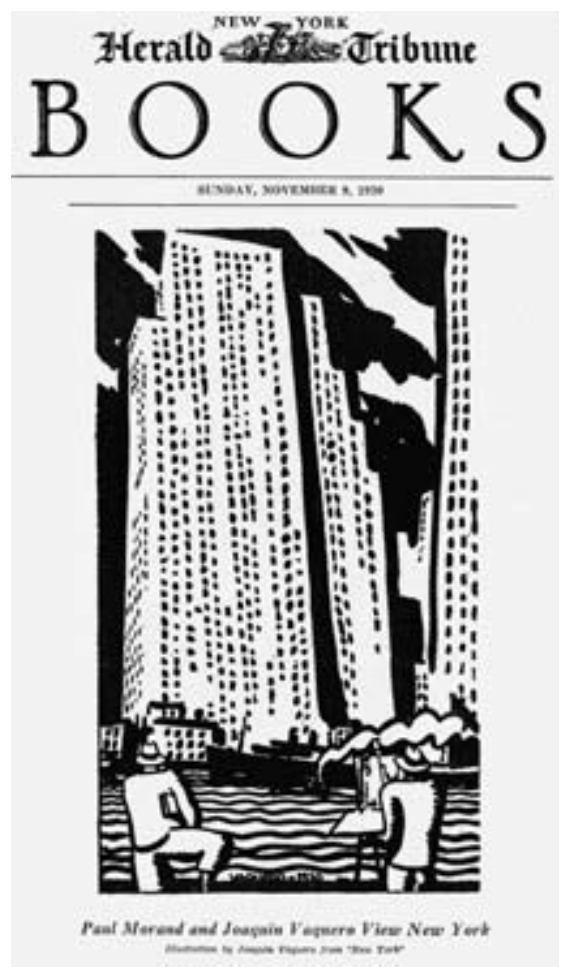

Fig. 18. Herald Tribune, Nueva York, 9-X-1930. Reproducción del dibujo de Vaquero Paul Morand and Joaquín Vaquero View New York.

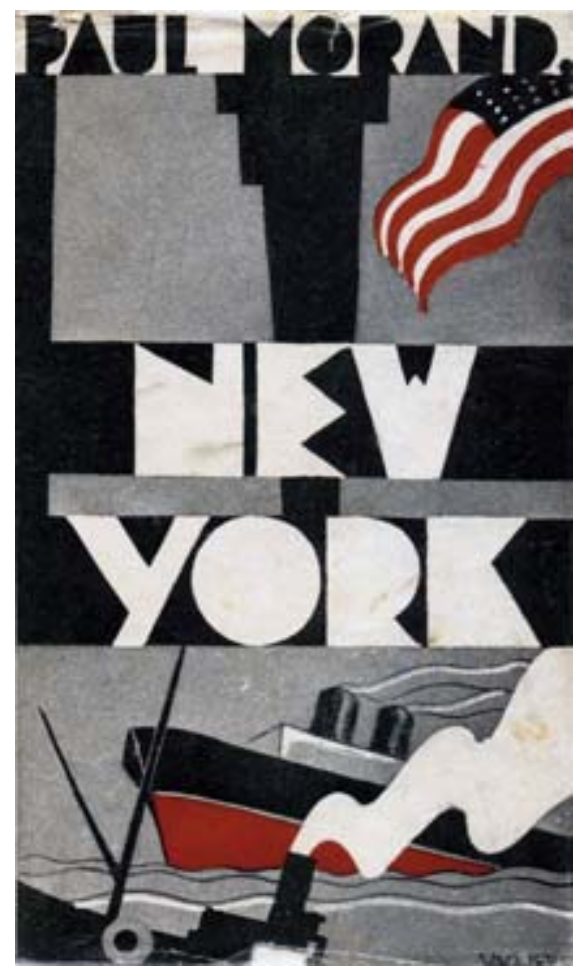

Fig. 19. Joaquín Vaquero, Portada del libro New York, 1930.

que las estancias de P. Morand en la gran metrópoli no coinciden con las del asturiano. Todo apunta a que el trabajo le fue encargado por mediación de su buen amigo en Nueva York, el crítico literario del New York Herald Tribune, Herschel Brickell, quien conocía sobradamente la capacidad de Vaquero para captar en sus dibujos la trepidante vida de la gran ciudad. Esta conjetura se vería fundamentada en la amplia cobertura informativa que dedicó este diario a la edición del libro cuando vio la luz en noviembre de 1930, reproduciendo a gran tamaño una de sus ilustraciones ${ }^{67}$ (fig. 18).

Vaquero ilustró el libro con catorce dibujos ${ }^{68}$ a página entera más el diseño de la cubierta, este último de clarísima filiación decó (fig. 19). En la portada reunió de forma admirable la estilización de los emblemas más característicos de la "era de la máquina" -el rascacielos y el transatlánti$\operatorname{co}^{69}$ - con una moderna tipografía geométrica derivada de los rótulos publicitarios que había con-

${ }^{67}$ Abundaría esta hipótesis la entrañable amistad que mantuvo con el crítico literario, quien visitó España en 1946 invitado por Vaquero, como así lo testifica una colección de fotografías conservadas en el archivo del pintor. En España, las revistas Cortijos y rascacielos y Obras se hicieron eco de las ilustraciones de Vaquero. Véase Fernández Shaw, 1932: 28-32, у BotelLA, 1933: 280-281.

${ }_{68}$ En realidad realizó veinte dibujos, de los cuales se reprodujeron finalmente catorce. Los otros seis originales, del tamaño de una tarjeta postal, los conservan los herederos del artista, constituyendo variaciones sobre el tema tan querido a Vaquero del Elevated.

${ }^{69}$ Weber, 1993: 29. 


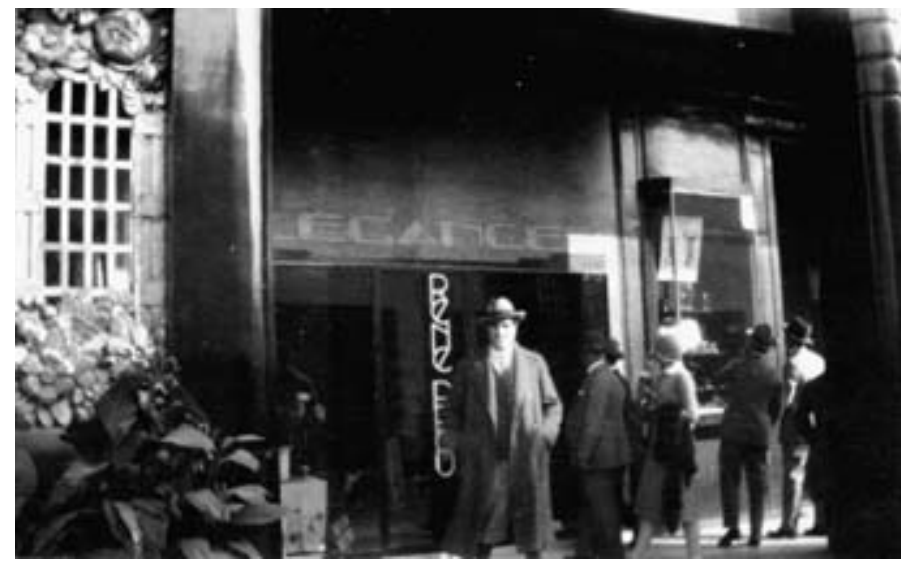

Fig. 20. Joaquín Vaquero en la Exposición Internacional de Artes Decorativas e Industriales Modernas de París (agosto de 1925).

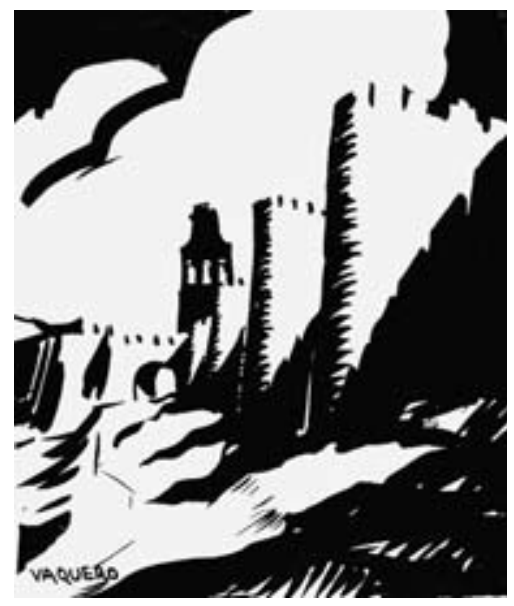

Fig. 21. Joaquín Vaquero, Ávila, ca. 1926. Tinta china y pincel sobre papel.

templado en la Exposición de 1925 (fig. 20). Si en algunos de sus dibujos quedaba patente la influencia de Ferriss en las perspectivas forzadas, Vaquero optó por una técnica más pictórica, sustituyendo el carboncillo del arquitecto visionario por el dibujo a tinta china y pincel ${ }^{70}$. Un procedimiento rápido y espontáneo que había experimentado durante su etapa de estudiante para tomar notas y apuntes de rincones castellanos, y en el que había demostrado su habilidad para sugerir con tintas planas la tercera dimensión (fig. 21). Otros dibujos evidenciaban la influencia de las fotografías tomadas en 1924 en Nueva York por el arquitecto alemán Erich Mendelsohn, fotografías que publicaría dos años después en su libro Amerika, Bilberbuch eines Architekten ${ }^{71}$. En todo caso, y sintonizando con la sensibilidad del escritor francés, Vaquero plasmó una ciudad llena de estrépito y agitación, de calles atestadas de letreros y anuncios desmesurados y atravesadas por "ferrocarriles aéreos". Sobre estas calles y avenidas se alzaban, inmensos, los rascacielos con su perfil tan característico que Morand comparaba con "escaleras sin barandillas"72 (figs. 22 y 23).

La estancia de los jóvenes arquitectos en Nueva York continuó con el estudio de algunos museos y puentes, referentes fundamentales toda vez que el programa del concurso prescribía que el monumento-faro debía contener un museo y de que el Parque Panamericano quedaría enlazado con la ciudad histórica de Santo Domingo a través de un puente de hierro que sustituiría al antiguo, destruido por el reciente ciclón que asoló la isla. Particularmente interesante les pareció el gigantesco puente colgante George Washington sobre el río Hudson, de $1067 \mathrm{~m}$ de luz, que a pesar de encontrarse inacabado mostraba ya concluidas sus torres, macizos de anclaje, cables de suspensión y péndolas ${ }^{73}$.

70 Egaña Casariego, 2010: 166.

71 El libro Amerika, Bilderbuch eines Architekten (América, álbum de un arquitecto) se publicó en 1926 por la editorial Rudolf Mosse de Berlín, y fue reeditado en 1928.

72 Morand, 1930: 25. A petición de su autor, el profesor Peter Conrad, esta misma colección de dibujos ilustró su libro The Art of the City, Views and Versions of New York, publicado por la Universidad de Oxford en 1984, como encabezamiento de cada uno de sus capítulos. Carlos Montes Serrano ha publicado recientemente un interesante artículo sobre los dibujos realizados el mismo año -1930-en Nueva York por Vaquero y Moya y Federico García Lorca, que, a pesar de no haber coincidido en la gran metrópoli, tuvieron un mentor común: el crítico literario Herschel Brickell. Véase MoNTES SERRANO, 2009: 57-68.

73 AVS. Vaquero Palacios y Moya Blanco, 1931a: 3. 

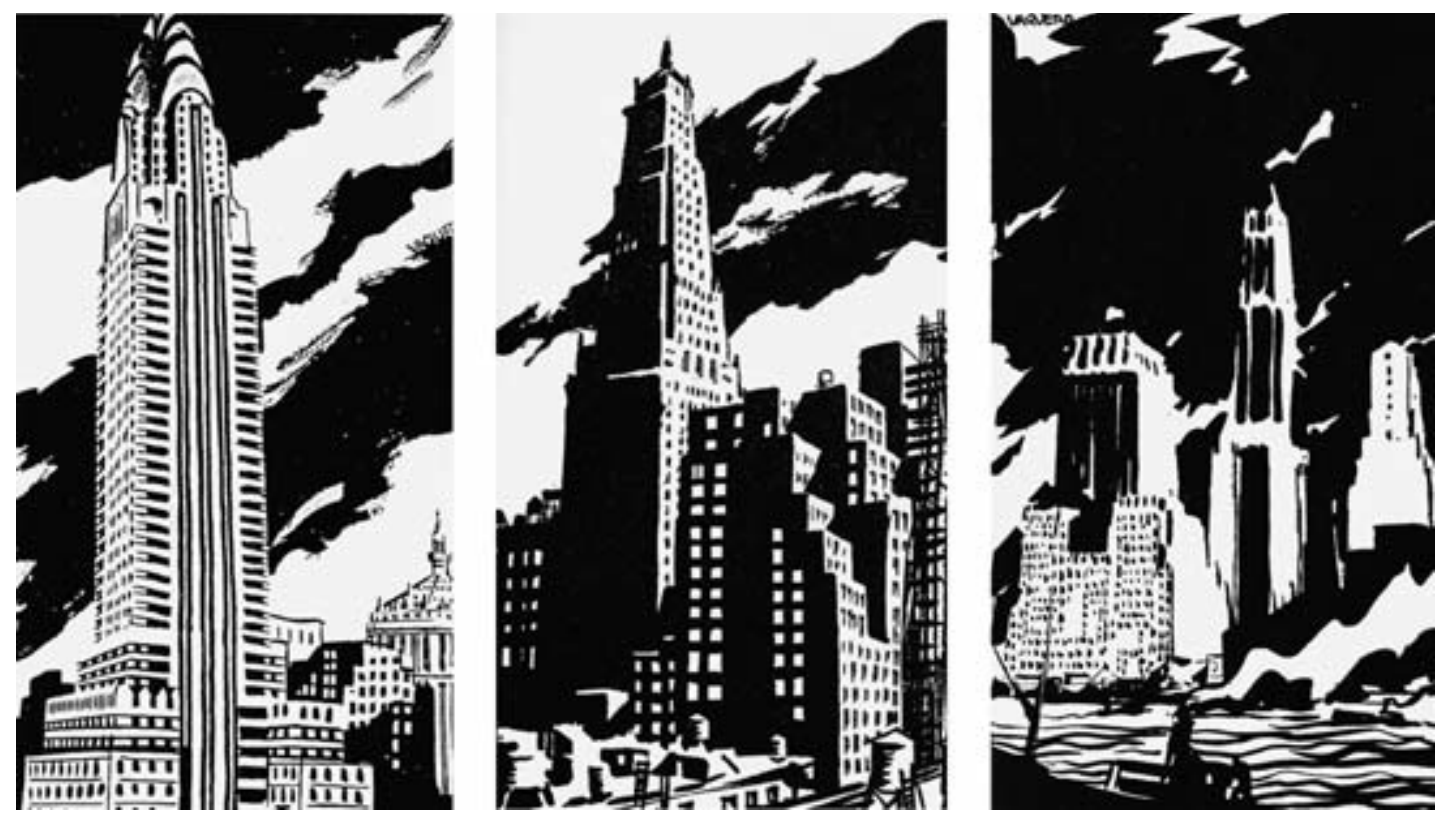

Fig. 22. Joaquín Vaquero, Chrysler Building, The Ritz Tower y The North River Water Front. Ilustraciones del libro New York, 1930.
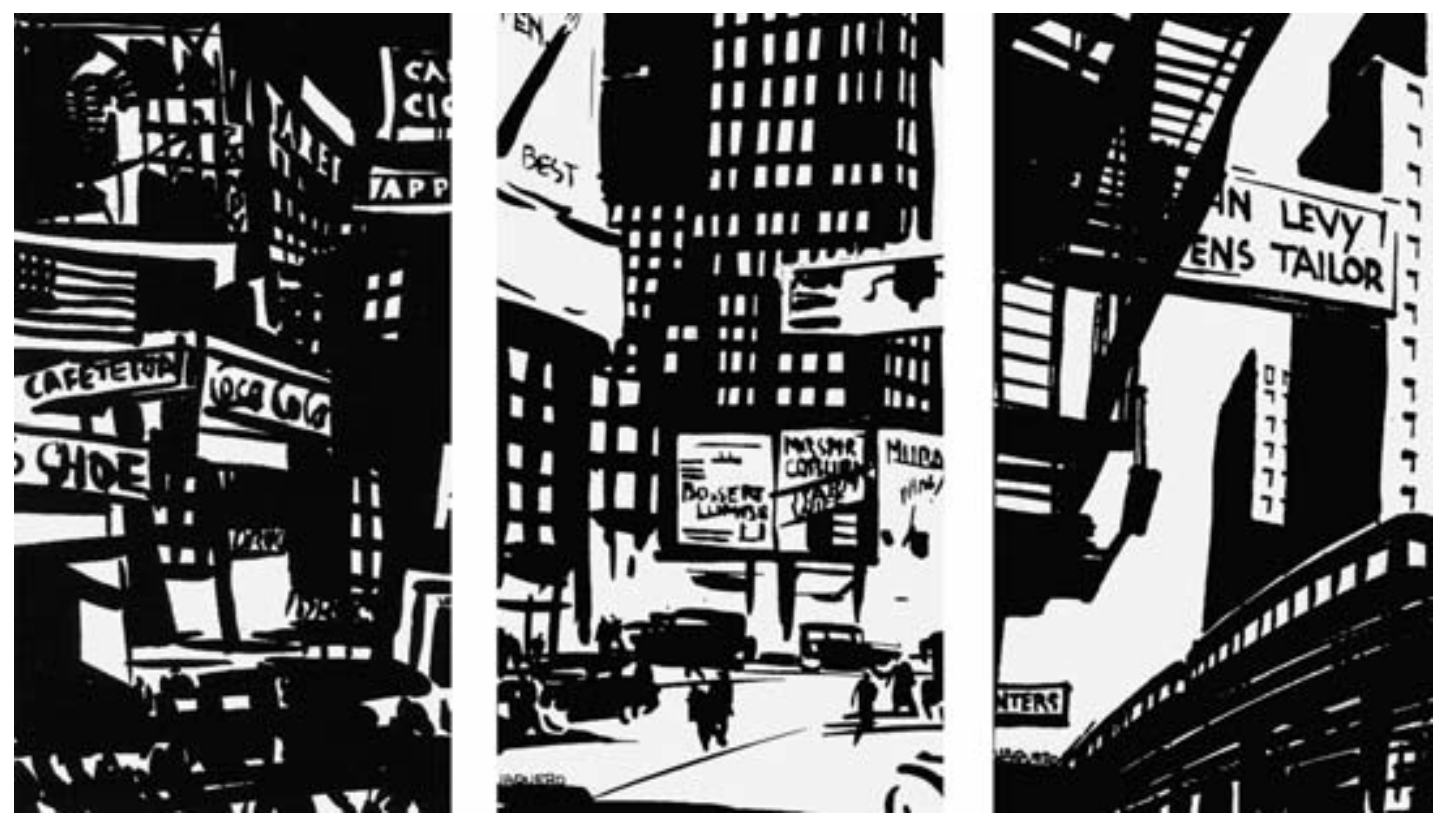

Fig. 23. Joaquín Vaquero, Advertising, Advertising y A Study in height. East Side. Ilustraciones del libro New York, 1930. 


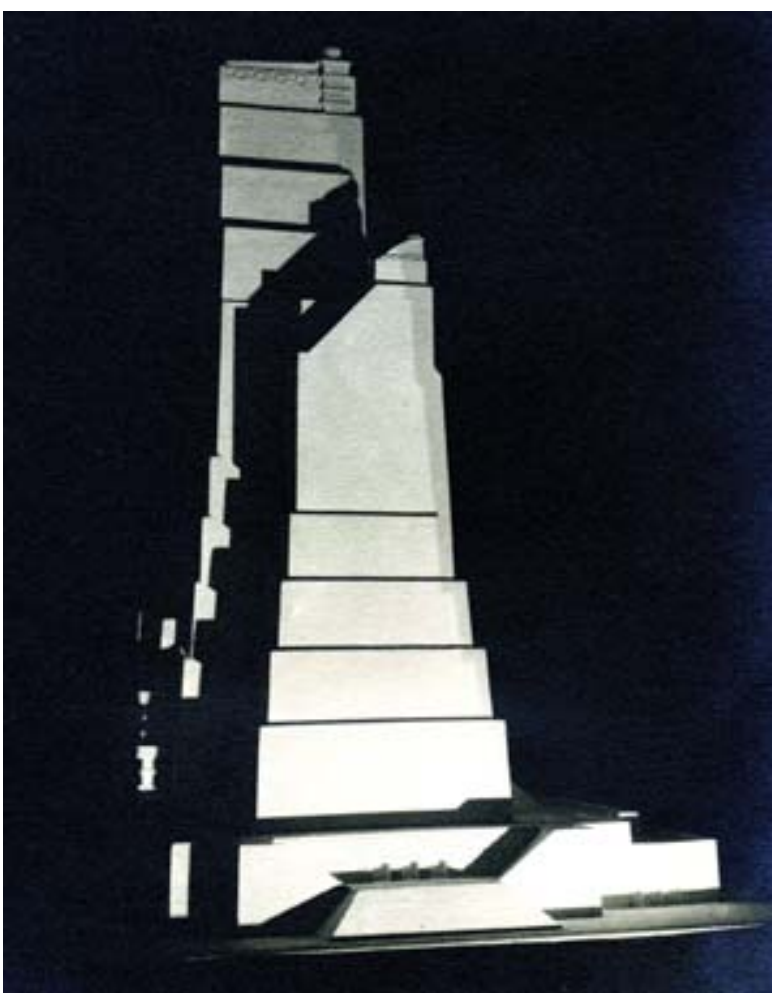

Fig. 24. Joaquín Vaquero y Luis Moya, Proyecto para el Faro de Colón, 1931. Maqueta del Faro. Archivo Vaquero, Segovia.
Buscando otras referencias útiles para su proyecto pasaron a Long Island, donde visitaron algunos faros importantes y las ciudades de recreo en las playas, como Southampton, East Hampton y Quogue, que mostraban algunas soluciones válidas para el Parque Panamericano que debían proyectar en Santo Domingo ${ }^{74}$. Tras dos semanas de frenética actividad en Nueva York estudiando los modernos sistemas de construcción de rascacielos y puentes, dibujando y pintando arquitecturas y paisajes urbanos, el 21 de septiembre prosiguieron su recorrido por otras ciudades importantes como Washington, Pittsburg, Chicago y Filadelfia.

Considerando finalizados sus estudios en los Estados Unidos, a finales de septiembre partieron hacia México para estudiar las ruinas precolombinas, cuyo repertorio decorativo pensaban adherir a su gigantesca pirámide-rascacielos. Durante más de un mes permanecieron en los principales yacimientos arqueológicos aztecas y mayas tomando fotografías, dibujando y pintando sus ruinas, lo que les resultó de gran ayuda en la definición del proyecto definitivo ${ }^{75}$.

Desde México pasaron, a través de Guatemala, a El Salvador ${ }^{76}$. Allí se embarcaron en el puerto de La Libertad para desembarcar en El Havre el día 22 de diciembre y continuar desde allí su viaje a España ${ }^{77}$. Instalados de nuevo en Madrid, Vaquero y Moya redactaron el proyecto definitivo que trasladaron ellos mismos con sus dibujos y maquetas a la ciudad de Río de Janeiro, donde en octubre de 1931 tuvo lugar la última fase del concurso y la proclamación del vencedor ${ }^{78}$ (fig. 24). El jurado, compuesto por los arquitectos Eliel Saarinen, Horacio Acosta y Lara y Frank Lloyd Wright -que había sustituido a Raymond Hood ocupado en el Rockefeller Center- les otorgó el tercer premio entre los diez proyectos finalistas ${ }^{79}$. Una resolución que no contentó en absoluto a los jóvenes españoles, al considerar que los proyectos clasificados en primer y segundo lugar incumplían claramente las

74 AVS. Vaquero Palacios y Moya Blanco, 1931a: 3.

75 Egaña Casariego, 2011: 96-102.

76 Castellano Rivas, 1930.

77 AVS. Vaquero Palacios y Moya Blanco, 1931a: 13; Egaña Casariego, 2012: 84-90.

78 AVS. Vaquero Palacios, 1931.

79 Una transcripción íntegra del acta del jurado puede verse en O Lapis, 3, Río de Janeiro, noviembre de 1931: 3-4. El crítico de arte José Francés, que años más tarde se ocupará ampliamente de la obra pictórica de Vaquero, lamentaba públicamente este fallo al considerar el proyecto español superior en muchos aspectos a los clasificados en primer y segundo lugar, firmados respectivamente por el inglés J. L. Gleave y los norteamericanos D. Nelson y E. Lynch. Francés, 1931. 
bases del concurso, al no haber erigido el faro en el punto obligado. Los días siguientes visitaron detenidamente la exposición de los proyectos, instalada en la Academia de Bellas Artes. Allí coincidieron con uno de los miembros del jurado, Frank Lloyd Wright, al que tuvieron ocasión de mostrarle su disconformidad con el fallo a la vista de los dibujos y maquetas. Como razón fundamental para haber calificado al margen de las bases argumentaba el célebre arquitecto que ninguno de los miembros del jurado había intervenido en su redacción, no estando en consecuencia obligados a cumplirlas. No atendiendo a estas y otras razones, Vaquero Moya publicaron estas conversaciones con Wright en la revista Arquitectura como muestra de la escasa seriedad con la que se había desarrollado esta segunda fase del concurso ${ }^{80}$.

\section{Algunas consideraciones finales}

Las primeras estancias de Vaquero en Nueva York constituyeron periodos de intensas experiencias estéticas y vitales que calaron hondamente en su sensibilidad. Desde el punto de vista arquitectónico, el conocimiento de los rascacielos decó que tanto le impresionaron y que le sirvieron de referente y estímulo para su proyecto del Faro de Colón. Además, la constatación de cómo las ideas llegadas de Europa eran desarrolladas maravillosamente desde un punto de vista tecnológico y a una escala por completo desconocida en el Viejo Continente. A la emoción de contemplar la construcción de aquellas gigantescas estructuras se añadió la revelación de los paisajes urbanos, con sus edificios renegridos envueltos en jirones de niebla. Un mundo dominado por los negros y los grises que, después de su pintura luminosa de Somiedo constituía un registro completamente nuevo para él y al que se entregó con verdadera pasión.

Concluida la aventura extraordinaria del Faro de Colón, Vaquero regresó a España para establecerse en Oviedo e incorporarse al estudio de su cuñado, el también pintor y arquitecto Francisco Casariego Terrero. Como arquitecto, inició allí el desarrollo de un lenguaje muy próximo al racionalismo del GATEPAC y directamente relacionado con la obra de su gran amigo José Manuel de Aizpúrua $^{81}$. Como pintor, su estancia en Nueva York se reveló como el catalizador de un cambio radical en su pintura, acentuándose en ella los tonos oscuros al preferir en su temática los paisajes carboneros de la cuenca minera, las escombreras y la carga del carbón en los barcos. Esta "Asturias negra", que constituía una prolongación natural de sus paisajes neoyorquinos, le condujo a extremar el estudio de las formas, muy construidas en aquel momento. Es su etapa de "las arquitecturas blancas y las pinturas negras", que se vio truncada por el estallido de la guerra civil y su traslado a Santiago de Compostela, donde se dedicó a la restauración de monumentos históricos y donde realizó una extensa colección de dibujos ${ }^{82}$. En los edificios que proyectó de nueva planta-Mercado de Santiago, 1938-1942- dejó constancia del profundo impacto que le causó la arquitectura monumental de la ciudad ${ }^{83}$.

Terminada la guerra, Vaquero retomó su inquieta andadura para viajar nuevamente por América y recalar periódicamente en Nueva York. Allí vivió importantes acontecimientos históricos, como el final de la Segunda Guerra Mundial anunciada por el Presidente Truman el 15 de agosto de $1945^{84}$. Vaquero conservaba entre sus papeles un ejemplar del New York Times con su primera plana

\footnotetext{
80 Vaquero Palacios y Moya Blanco, 1932: 110-133; Egaña Casariego, 2012: 84-90.

81 Morales Saro, 1981: 228 y ss.

${ }^{82}$ Una porción de estos dibujos fueron expuestos años después, junto a otros de su hijo, el pintor y escultor Joaquín Vaquero Turcios, en el Instituto Padre Sarmiento de Estudios Gallegos de Santiago de Compostela. SánCHEz CANTÓN, 1954.

83 Vaquero Palacios, 1983: 3-8.

84 AVS. Vaquero Palacios, Biografía incompleta, 146.
} 

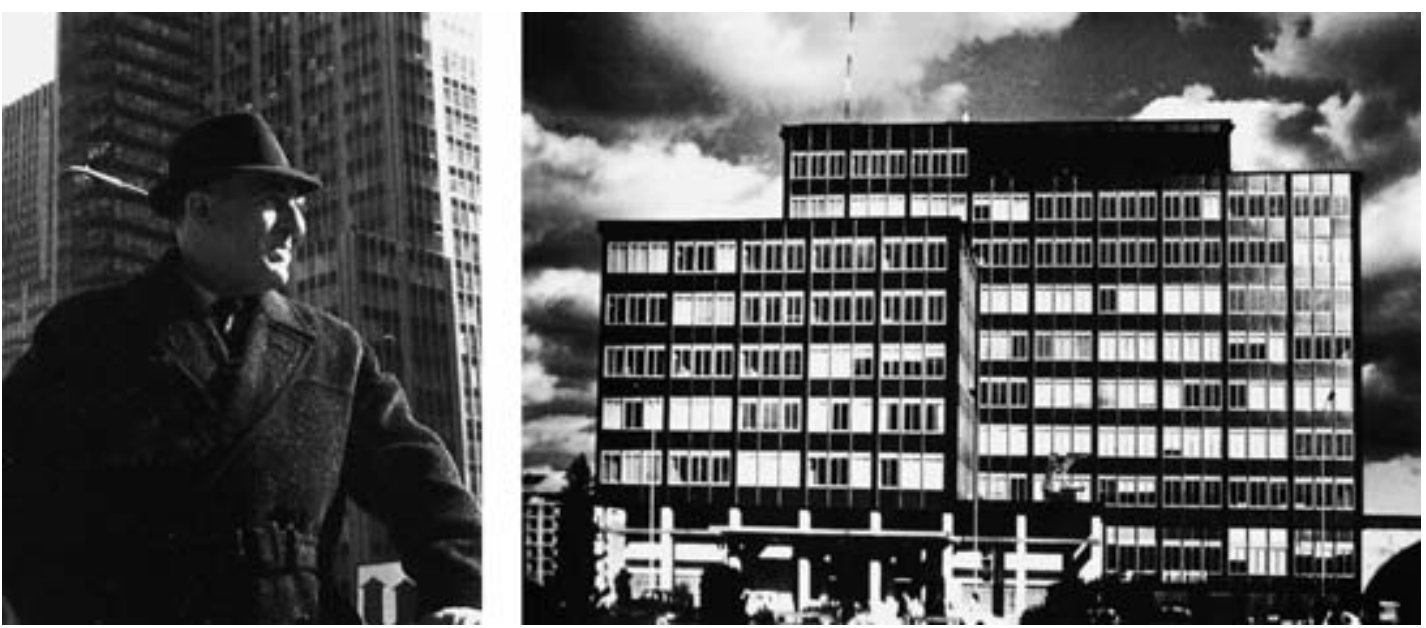

Fig. 25. Joaquín Vaquero en la terraza de su hotel de Nueva Nueva York (1963). Fotografía: Joaquín Vaquero Turcios. Joaquín Vaquero, Edificio Social de Hidroeléctrica del Cantábrico, Oviedo (1963-1969).

ocupada totalmente por el titular "War is over", y el recuerdo imborrable del espectáculo de la lluvia de papelitos cayendo desde todas las ventanas de la ciudad. Y es que Nueva York constituyó un componente muy significativo no sólo en su obra sino también en su vida.

En 1963 volvió a Nueva York para exponer en la Gallery 63 (721 Madison Avenue) los paisajes antropomorfos pintados durante sus años de residencia en Italia ${ }^{85}$. Algunos años después, en diciembre de 1968, inauguró con sus paisajes castellanos la sucursal neoyorquina de la madrileña galería Kreisler (789 Madison Avenue at 67th Street), dedicada a artistas españoles ${ }^{86}$. Durante su estancia en la ciudad admiró el nuevo estilo de sus rascacielos, que derogada la ley de zonificación de 1916 se erguían como volúmenes prismáticos cerrados por muros cortina. La contemplación de uno de estos edificios inspirados en Mies van der Rohe frente a la habitación de su hotel, le sugirió el edificio social de Hidroeléctrica del Cantábrico en Oviedo (1969), que proyectó a su regreso a España ${ }^{87}$ (fig. 25).

Podría afirmarse, para concluir, que Vaquero mantuvo hasta el final de sus días la añoranza de Nueva York, la metrópoli donde obtuvo sus primeros éxitos y que marcó el inicio de su carrera profesional. Durante la última década de su vida, dedicada a la pintura de sueños y recuerdos, el nonagenario artista evocó con frecuencia desde su estudio segoviano -y frente a los campos amarillos castellanos- los paisajes sombríos de Nueva York que tan alta significación alcanzaron en su obra. Por lo demás, Vaquero conservó siempre con especial esmero aquella primera edición del libro de Ferriss adquirido en 1930 en Nueva York, volviendo sobre él con frecuencia para admirar sus dibujos y reavivar recuerdos de juventud.

${ }^{85}$ La exposición estuvo colgada del 5 al 23 de marzo, coincidiendo de lleno con la huelga de la prensa neoyorquina, por lo que no hubo crítica.

${ }^{86}$ CLARK, 1968.

87 Vaquero Palacios, 1989: 84-91. 


\section{BIBLIOGRAFÍA}

Acosta y Lara, Horacio, "Monumento-Faro a Colón. Concurso Internacional", conferencia pronunciada en la Sociedad de Arquitectos de Uruguay el 8 de octubre de 1946, Montevideo, 1949.

Aguilera Cerni, Vicente, Vaquero, Instituto de Estudios Asturianos, Oviedo, 1980.

Alcántara, Francisco, "Un alumno de la Escuela de Arquitectura, paisajista", El Sol, Madrid, 16-III-1926.

Almenar, "Los asturianos que triunfan. Charlando con el arquitecto ovetense don Joaquín Vaquero, acerca del faro monumental de Colón en la ciudad de Santo Domingo", La Voz de Asturias, n. ${ }^{\circ}$ 1982, Oviedo, 1929.

Anasagasti, Teodoro, "Los arquitectos pintores", Arquitectura, 84 (abril 1926), 165-166.

Botella, Antonio, "Dibujos de J. Vaquero", Obras (julio 1933), 280-281.

Bradomín (Antonio Onieva), "Visitando la exposición Vaquero", La Voz de Asturias, Oviedo, 24-IX-1924.

Carantoña, Francisco, Evaristo Valle (1873-1951), Fundación Museo Evaristo Valle, Gijón, 1986.

Capitel, Antón, "La arquitectura de un artista: JVP, plural y múltiple”, en AA. VV., Joaquín Vaquero Palacios (1900-1998), Consejo Superior de los Colegios de Arquitectos de España (1998), 12-25.

Castellano Rivas, J., “Un gran pintor en San Salvador”, Patria, San Salvador, 14-X-1930.

Clark, Margarita, "Joaquín Vaquero, Spanish Artist, opens in New York”, Manhattan East, Nueva York, 20XII-1968.

Conrad, Peter, The Art of the City. Views and Versions of New York, Oxford University Press, Nueva York, 1984.

Egaña Casariego, Francisco, Vaquero, Colegio Oficial de Aparejadores y Arquitectos Técnicos del Principado de Asturias y Ediciones Trea, Gijón, 2008.

Egaña Casariego, Francisco, "El Concurso Internacional para el Faro de Colón. El proyecto español premiado", Goya, 331 (abril-junio 2010), 158-177.

Egaña Casariego, Francisco, "Pirámides y rascacielos. El viaje de los arquitectos Luis Moya y Joaquín Vaquero a Estados Unidos y Centroamérica (1930)", Liño, 17 (2011), 91-103.

Egaña Casariego, Francisco, "El viaje de los arquitectos Luis Moya y Joaquín Vaquero a Río de Janeiro. El desenlace del Concurso para el Faro de Colón (1931)", Liño, 18 (2012), 77-90.

Fernández Shaw, Casto, “Admirables ilustraciones para el libro de Paul Morand 'New York del notable pintor-arquitecto Sr. Vaquero", Cortijos y rascacielos, 9 (1932), 28-32.

Fonseca, "Joaquín Vaquero", La Prensa, Gijón, 21-IX-1924.

Francés, José, "La semana artística", Nuevo Mundo, Madrid, 7-XI-1931: 24-25.

Franco de Espes, L., "Por la raza y la historia es preciso que la obra gigante del Faro de Colón sea realizada por artistas españoles", La Esfera, n. ${ }^{\circ} 877,25-X-1930$.

Fulton, Deoch, “Joaquín Vaquero Knoedler Galleries”, The Art News, Nueva York, 31-III-1928.

García, Graciano, "Asturianos de hoy, nombres para siempre. Noticias de la vida de Joaquín Vaquero", $L a$ Nueva España, Oviedo, 23-IV-1966.

García Bandrés, Luis J., “Encuentro con Vaquero Palacios”, Heraldo de Aragón, 18-XI-1979.

García-Gutiérrez Mosterio, Javier, "Los distintos usos del dibujo de arquitectura en Luis Moya Blanco", Academia, 77 (2 sem. 1993), 245-294.

Gómez Santos, Marino, Francisco Casariego. Joaquín Vaquero, Oviedo, 1974.

González Capitel, Antonio y García-Gutiérrez Mosteiro, Javier, Luis Moya Blanco arquitecto 1904-1990, Madrid, 2000.

Hughes, Robert, Visiones de América. La historia épica del arte norteamericano, Barcelona, 2001.

Kelsey, Albert, Programa y Reglamento del Concurso para la selección de un arquitecto para el Faro Monumental que las naciones del mundo erigirán en la República Dominicana a la memoria de Cristóbal Colón, Unión Panamericana, Washington, 1928.

López Pineda, Julián, “Un prestigioso artista en San Salvador”, Diario Latino, San Salvador, 2-VII-1928.

Martínez de Rivas, Carlos, Vaquero, Dirección General de Bellas Artes, Madrid, 1966.

Montes Serrano, Carlos, "Nosotros somos latinos. Españoles dibujando en Nueva York, 1930”, RA, 11 (2009), 57-68.

Morand, Paul, New York, Henry Holt \& Co., Nueva York, 1930.

Morales Saro, María de las Cruces, Oviedo. Arquitectura y desarrollo urbano. Del eclecticismo al movimiento moderno, Universidad de Oviedo, 1981.

Arch. esp. arte, LXXXVI, 343, JULIO-SEPTIEMBRE 2013, 237-262, ISSN: 0004-0428 
Palmer, M., “Joaquín Vaquero”, The Times, Nueva York, 1-IV-1928.

Pearson, Margherite, "Vaquero", Post, Nueva York, 7-IV-1928.

Pérez Lastra, José Antonio, Vaquero Palacios. Arquitecto, Colegio Oficial de Arquitectos de Asturias, Oviedo, 1992.

Pozo, José Manuel y García-Diego Villarías, Héctor (eds.), Viajes en la transición de la arquitectura española hacia la modernidad, Actas del Congreso organizado por la Escuela Superior de Arquitectura de la Universidad de Navarra, Pamplona, 6/7 de mayo de 2010.

San Antonio Gómez, Carlos de (ed.), Revista Arquitectura (1918-1936), Ministerio de Fomento y Colegio Oficial de Arquitectos de Madrid, Madrid, 2001.

Sánchez Cantón, F. J., Dibujos de Vaquero Palacios y Vaquero Turcios, cat. exp., Instituto Padre Sarmiento de Estudios Gallegos, Santiago de Compostela, julio de 1954.

Solís, Ramón, Vaquero, Ministerio de Educación y Ciencia, Madrid, 1973.

Stephens, Jessica, "Joaquín Vaquero", Apolo, Londres, diciembre, 1930.

Subirats, Eduardo, La transfiguración de la noche (La utopía arquitectónica de Hugh Ferris), Colegio Oficial de Arquitectos de Málaga, 1992.

Tafuri, Manfredo, "The New Babilon: los 'gigantes amarillos" y el mito del americanismo. Expresionismo, Jazz Style, rascacielos, 1913-1930”, en La esfera y el laberinto. Vanguardias y arquitectura de Piranesi a los años setenta, Barcelona, 1984, 201-230.

Teroll, E., "Madrid", The Art News, Nueva York, 10-IV-1926.

Vaquero Palacios, Joaquín y Moya Blanco, Luis, Memoria del viaje de estudio por América realizado por los arquitectos Joaquín Vaquero y Luis Moya, representantes por España en el concurso mundial para el Faro de Colón, (13 págs.), Madrid (8-II-1931), mecan (AVS).

Vaquero Palacios, Joaquín y Moya Blanco, Luis, Memoria descriptiva del Faro a la memoria de Colón en Santo Domingo (14 pp.), Madrid (1931), mecan (AVS).

Vaquero Palacios, Joaquín, Diario de viaje a Río de Janeiro llevando los dibujos y maquetas para el concurso del Faro de Colón, 1931 (AVS).

Vaquero Palacios, Joaquín y Moya Blanco, Luis, "Resultado del Concurso para el Faro de Colón”, Arquitectura, 156 (abril 1932), 110-133.

Vaquero Palacios, Joaquín, "El Mercado de Santiago de Compostela", Composición arquitectónica, 1, San Sebastián, 1983, 3-8.

Vaquero Palacios, Joaquín, "Edificio social de Hidroeléctrica del Cantábrico en Oviedo", en AA. VV., Arquitectura-Arte-Ingeniería. La obra integradora de Joaquín Vaquero en Asturias, Hidroeléctrica del Cantábrico y Colegio Oficial de Arquitectos de Asturias, Oviedo, 1989, 84-91.

Vaquero Palacios, Joaquín, “A la memoria de Luis Moya Blanco”, Academia, 70 (1er sem. 1990), 25-28.

Weber, Eva, Art Deco, Madrid, 1993.

Fecha de recepción: 29-III-2012

Fecha de aceptación: 1-X-2012 